\title{
Inflammation and Ectopic Fat Deposition in the Aging Murine Liver Is Influenced by CCR2
}

Elizabeth C. Stahl, ${ }^{* \dagger}$ Evan R. Delgado, ${ }^{* \dagger}$ Frances Alencastro, ${ }^{* \dagger}$ Samuel T. LoPresti, ${ }^{* \dagger}$ Patrick D. Wilkinson, ${ }^{* \dagger}$ Nairita Roy, ${ }^{* \dagger}$ Martin J. Haschak, ${ }^{* \ddagger}$ Clint D. Skillen, ${ }^{*}$ Satdarshan P. Monga, ${ }^{* \dagger \S}$ Andrew W. Duncan, ${ }^{* \dagger \S}$ and Bryan N. Brown ${ }^{* \ddagger \S}$

From the McGowan Institute for Regenerative Medicine, $*$ the Bioengineering Department, ${ }^{\ddagger}$ Swanson School of Engineering, and the Pittsburgh Liver Research Center, ${ }^{\S}$ and the Department of Pathology, ${ }^{\dagger}$ University of Pittsburgh School of Medicine, University of Pittsburgh, Pittsburgh, Pennsylvania

Accepted for publication

October 22, 2019.

Address correspondence to Bryan N. Brown, Ph.D., Bioengineering Department, McGowan Institute for Regenerative Medicine, Pittsburgh Liver Research Center, University of Pittsburgh, 450 Technology Dr., Ste. 300, Pittsburgh, PA 15219; or Andrew W. Duncan, Ph.D., Department of Pathology, McGowan Institute for Regenerative Medicine, Pittsburgh Liver Research Center, University of Pittsburgh, 450 Technology Dr., Ste. 300, Pittsburgh, PA 15219. E-mail: brownb@ upmc.edu orduncana@pitt.edu.

\begin{abstract}
Aging is associated with inflammation and metabolic syndrome, which manifests in the liver as nonalcoholic fatty liver disease (NAFLD). NAFLD can range in severity from steatosis to fibrotic steatohepatitis and is a major cause of hepatic morbidity. However, the pathogenesis of NAFLD in naturally aged animals is unclear. Herein, we performed a comprehensive study of lipid content and inflammatory signature of livers in 19-month-old aged female mice. These animals exhibited increased body and liver weight, hepatic triglycerides, and inflammatory gene expression compared with 3-month-old young controls. The aged mice also had a significant increase in $\mathrm{F} 4 / 80^{+}$hepatic macrophages, which coexpressed $C D 11 b$, suggesting a circulating monocyte origin. A global knockout of the receptor for monocyte chemoattractant protein (CCR2) prevented excess steatosis and inflammation in aging livers but did not reduce the number of $C D 11 b^{+}$macrophages, suggesting changes in macrophage accumulation precede or are independent from chemokine ( $\mathrm{C}-\mathrm{C}$ motif) ligand -CCR2 signaling in the development of age-related NAFLD. RNA sequencing further elucidated complex changes in inflammatory and metabolic gene expression in the aging liver. In conclusion, we report a previously unknown accumulation of $\mathrm{CD}_{11} \mathrm{~b}^{+}$macrophages in aged livers with robust inflammatory and metabolic transcriptomic changes. A better understanding of the hallmarks of aging in the liver will be crucial in the development of preventive measures and treatments for endstage liver disease in elderly patients. (Am J Pathol 2020, 190: 372-387; https://doi.org/10.1016/ j.ajpath.2019.10.016)
\end{abstract}

Nonalcoholic steatohepatitis (NASH) is the leading cause of chronic liver disease in the world and is currently the second leading indication for liver transplantation in the United States. $^{1-3}$ The prevalence of nonalcoholic fatty liver disease (NAFLD), including NASH, increases with age. ${ }^{1}$ Individuals aged $>60$ years exhibit a $200 \%$ increase in liver triglyceride content compared with young individuals when matched for body mass index, fat percentage, physical activity, smoking, and medical history. ${ }^{4}$ With an aging population, the number of individuals requiring a liver transplant is expected to increase, whereas the number of healthy donor organs available for transplant is anticipated to decrease as hepatic steatosis risk factors (eg, obesity and type 2 diabetes mellitus) continue to increase, further exacerbating the disparities in liver transplantation supply and demand.
The mechanism for developing age-related steatosis is not fully understood but was recently attributed to hepatocyte senescence driving a reduction in mitochondrial fatty acid

Supported by NIH grants R01-AG055564 (B.N.B.), R01-DK103645 (A.W.D.), F31-DK112633 (E.C.S.), U24-DK059637, and P30-DK020593; the Cellular Approaches to Tissue Engineering and Regeneration T32 training grant T32-EB001026 (E.C.S., S.T.L., and M.J.H.); the Pittsburgh Liver Research Center Pilot and Feasibility Award P30-DK120531 (B.N.B.).

Disclosures: None declared

Current address of E.C.S., California Institute for Quantitative Biosciences, University of California Berkeley, Berkeley, CA; of S.T.L, Department of Chemical Engineering, Carnegie Mellon University, Pittsburgh, PA; of P.D.W., Division of Genetics, Brigham and Women's Hospital, Harvard Medical School, Boston, MA.

The content is solely the responsibility of the authors and does not necessarily represent the official views of the NIH. 
metabolism. ${ }^{5}$ Progression of NAFLD/NASH in aged individuals may also be related to decreased transport of insulin across the sinusoidal endothelium, ${ }^{6}$ reduction in autophagic flux, ${ }^{7}$ or chronic low-level inflammation originating from adipose tissue or local immune cells, ${ }^{8,9}$ leading to the buildup of toxic free fatty acids in the liver.

Hepatic macrophages, including both Kupffer cells and monocyte-derived macrophages, have been implicated in the development and progression of NAFLD/NASH, but little is known about how aging influences these cell populations. ${ }^{10-12}$ Kupffer cells are derived from the embryonic yolk sac and are maintained by self-renewal, comprising the largest population of immune cells in the liver. ${ }^{13-16}$ Alternatively, monocyte-derived macrophages have been found to migrate to the liver under chemotactic stimuli and constitute a distinct population in the absence of Kupffer cell depletion. ${ }^{17,18}$

When mice were fed a high-fat or high-cholesterol diet, the balance of hepatic macrophages was found to shift toward monocyte-derived cells $\left(\mathrm{F} 4 / 80^{\mathrm{lo}} \mathrm{CD} 68^{-} \mathrm{CD} 11 \mathrm{~b}^{\mathrm{hi}}\right)$ and away from the resident Kupffer cell population (F4/ $\left.80^{\text {hi }} \mathrm{CD} 68^{+} \mathrm{CD} 11 \mathrm{~b}^{\text {lo }}\right) .{ }^{19}$ Hepatic macrophages are known to secrete IL- $1 \beta$, tumor necrosis factor- $\alpha$, and chemokine (C-C motif) ligand (CCL) 5 during steatosis, which may promote hepatocyte apoptosis, as well as monocyte chemoattractant protein (CCL2), which can also be produced by hepatocytes. ${ }^{20}$ The production of CCL2 is regulated by the canonical NF- $\kappa \mathrm{B}$ signaling pathway and is inversely correlated to liver $\mathrm{X}$ receptor and retinoid $\mathrm{X}$ receptor signaling in both macrophages and hepatocytes. ${ }^{21}$

This study investigates hepatic steatosis in aging mice, and identifies phenotypical and functional changes in hepatic macrophages, toward a better understanding of mechanisms underlying the development of fatty liver disease and inflammation in the natural aging process.

\section{Materials and Methods}

\section{Animal Models}

The Institutional Animal Care and Use Committee of the University of Pittsburgh (Pittsburgh, PA) approved all mouse experiments. C57BL/6 wild-type (WT) mice were obtained at the ages of 2 and 18 months from the National Institute on Aging (NIA) Rodent Colony (Charles River Laboratories, Wilmington, MA), where they received the NIH 31 diet (Ziegler Feed, Gardners, PA) and were used for experiments 1 month after arrival. CCR2 knockout (KO) mice (B6.129S4-CCr2 $<$ tm1lfc $>$ ) or WT controls were obtained from The Jackson Laboratory (Bar Harbor, ME) as retired breeders ( 7 to 8 months of age), where they received JL Rat and Mouse Auto 6F (LabDiet, St. Louis, MO) and were aged in house at the University of Pittsburgh for an additional 11 to 12 months, where they received Prolab Isopro RMH 3000 (Lab Diet). Female mice were included exclusively in this study, as sex-specific differences in the age of onset of NAFLD/NASH have been noted in the literature. ${ }^{22}$ Females are more likely to develop NAFLD/ NASH with aging and after menopause, whereas males are less well associated with age as a risk factor for developing NAFLD/NASH. ${ }^{22}$ Mice were maintained on a standard 12hour light and 12-hour dark system at the University of Pittsburgh specific pathogen-free animal facility. Mice were housed in Optimice cages (AnimalCare Systems, Centennial, CO) with Sani-Chip Coarse bedding (P.J. Murphy, Montville, NJ) and provided ad libitum access to water. Mice were provided huts and running wheels for enrichment.

\section{Harvest of Liver Tissues}

Mice were weighed and sacrificed by carbon dioxide inhalation, followed by cervical dislocation, in accordance with University of Pittsburgh Institutional Animal Care and Use Committee standards. Livers were excised and rinsed in phosphate-buffered saline (PBS). Liver mass was recorded. Small pieces of liver were dissected and i) fixed in $2 \%$ paraformaldehyde (Acros Organics; Fisher Scientific, Pittsburgh, PA) for 2 hours, followed by $60 \%$ sucrose overnight, then embedded in OCT compound (Fisher Scientific); ii) fixed in 10\% neutral-buffered formalin (Fisher Scientific) and embedded into paraffin blocks by the McGowan Institute for Regenerative Medicine histology core; or iii) snap frozen in liquid nitrogen and stored at $-80^{\circ} \mathrm{C}$ for later analysis of RNA, protein, or lipids.

\section{Primary Liver Cell Isolation}

Primary hepatocytes were isolated using a two-step collagenase perfusion. ${ }^{23}$ Briefly, after general anesthesia induction, a catheter was inserted into the portal vein or inferior vena cava and $0.3 \mathrm{mg} / \mathrm{mL}$ collagenase II (Worthington, Lakewood, NJ) was circulated through the liver. Digested livers were placed in Dulbecco's modified Eagle's medium with 10\% fetal bovine serum (Corning, Tewksburg, MA), passed through 100- and 70- $\mu \mathrm{m}$ cell strainers, and washed twice using low-speed centrifugation $(50 \times g$ for 3 minutes) to remove nonparenchymal cells (NPCs). Hepatocyte viability, determined by trypan blue staining, was typically $>80 \%$, with purity $>90 \%$. Hepatocytes were stored in RNA-later (Fisher Scientific) or radioimmunoprecipitation assay (RIPA) buffer (1\% IgePAL CA-630 [octylphenoxy poly(ethyleneoxy)ethanol], $0.5 \%$ sodium deoxycholate, and $0.1 \%$ SDS; Sigma-Aldrich, St. Louis, MO), with Pierce protease and phosphatase inhibitor mini tablet (ThermoScientific, Waltham, MA) at $-20^{\circ} \mathrm{C}$ for RNA/protein analysis at a later time. NPCs were used for flow cytometry or were further purified to collect hepatic macrophages. Briefly, NPCs were blocked with Fc receptor (1:100; rat anti-mouse CD16/32; BD Biosciences, San Jose, CA), stained with F4/80-phosphatidylethanolamine (F4/80-PE) [1:20; rat anti-mouse (BM8); eBioscience, ThermoFisher 
Scientific, San Diego, CA], and incubated with anti-PE microbeads (1:10; Miltenyi Biotec, Auburn, CA). Cells were applied to LS columns on the QuadroMACS separator (Miltenyi Biotec) and washed three times to remove nontagged NPCs. F4/80 $0^{+}$cells were eluted and counted. Viability of collected $\mathrm{F} / 80^{+}$cells was typically $>85 \%$, with purity $>95 \%$.

\section{Serum Quantification}

Serum was collected from experimental animals; and the levels of circulating proteins, including alanine transaminase (ALT), aspartate transaminase (AST), albumin, and total bilirubin, or serum cholesterol and triglycerides were determined by the University of Pittsburgh Medical Center Clinical Laboratory.

\section{Hepatic Lipid Quantification}

Frozen liver pieces (approximately $100 \mathrm{mg}$ ) were shipped overnight on dry ice to the Lipids and Lipoproteins Subcore at the Vanderbilt Mouse Metabolic Phenotyping Center Analytical Resources Core (Nashville, TN). Lipids were extracted from liver tissue by thin-layer chromatography, and total cholesterol, triglycerides, and fatty acids were quantified by gas chromatography.

\section{Hepatic Bile Acid Quantification}

Frozen liver pieces (approximately $100 \mathrm{mg}$ ) were homogenized in $75 \%$ ethanol (DeconLabs, King of Prussia, PA) and incubated at $50^{\circ} \mathrm{C}$ for 2 hours. Digested lysates were centrifuged at $6000 \times g$ for 10 minutes, and the supernatant was collected. Bile acids were quantified using the Mouse Total Bile Acids Kit (Crystal Chem, Elk Grove Village, IL).

\section{Glucose Tolerance Test}

Glucose levels were measured from blood using EmbracePRO glucose monitor (Omnis Health, Nashville, TN) after 6 hours of fasting. Mice received i.p. injection of $10 \%$ D-glucose solution $(1 \mathrm{~g} / \mathrm{kg}$; Fisher Scientific). Levels of glucose in the blood were measured at $15,30,60$, and 120 minutes after injection and recorded.

\section{Liver Histology and Immunostaining}

Paraffin blocks were divided into sections ( $4 \mu \mathrm{m}$ thick) and affixed to glass slides. Sections were deparaffinized using xylene and graded ethanol (100\% to $95 \%)$ washes and then placed in tap water. Hematoxylin and eosin, Masson trichrome, and Picrosirius red staining was performed in house, according to standard protocols (Sigma-Aldrich). Staining was performed by the McGowan Institute for Regenerative Medicine histology core using ApopTag Peroxidase In Situ Apoptosis Detection Kit (EMD
Millipore, Burlington MA). OCT blocks were divided into sections ( $7 \mu \mathrm{m}$ thick) and affixed to glass slides. Sections were brought to room temperature for 10 minutes, then stained with Oil Red O (Sigma-Aldrich), or blocked with 5\% donkey serum (Fisher Scientific), 1\% bovine serum albumin (Sigma-Aldrich), and $0.01 \%$ Triton X-Tween 20 (Fisher Scientific) for 1 hour for immunostaining. Primary antibodies, rabbit anti-mouse CD68 (ab125212; 1:250; Abcam, Cambridge, MA), rat anti-mouse CD11b (550282; 1:100; BD Biosciences, San Jose, CA), or rabbit anti-p21 (sc-471; Santa Cruz Biotechnology Inc., Dallas, TX), were applied to tissue sections overnight at $4^{\circ} \mathrm{C}$. Slides were washed three times in PBS, then secondary antibodies were applied for 1 hour at 1:250 dilution (donkey anti-rabbit 647 or donkey anti-rat 594; ThermoFisher Scientific). Slides were washed three times in PBS, then blocked in 5\% rat serum (ThermoFisher Scientific) for 1 hour at room temperature. F4/80-FITC (ab105155; 1:50; Abcam) was applied for 1 hour at room temperature. Slides were washed three times in PBS, counterstained with DAPI (BioLegend, San Diego, CA), mounted, and coverslipped. Light microscopy was performed on Eclipse50i microscope (Nikon Instruments Inc., Melville, NY). Fluorescence microscopy was performed on EclipseTiU (Nikon Instruments Inc.). Staining was quantitated in ImageJ software version 1.50i (NIH, Bethesda, MD; http://imagej.nih.gov/ij) or NIS Elements Basic Research software version 4.13 (Nikon Instruments Inc.).

\section{Gene Expression}

RNA-later solution was removed from cell pellets. RNA was isolated using the RNeasy mini kit (Qiagen, Gaithersburg, MD). Briefly, cells were lysed with the RLT buffer and 70\% ethanol, then applied to spin columns, washed, and eluted, per the manufacturer's directions. RNA was quantified using a NanoDrop Lite Spectrophotometer (ThermoFisher Scientific). cDNA was generated using the RNA-to-cDNA kit (Applied Biosystems, Foster City, CA). Quantitative RTPCR was performed with $10 \mu \mathrm{g}$ of cDNA, TaqMan Gene Expression Master Mix (ThermoFisher Scientific), and TaqMan primers (ThermoFisher Scientific) on the Quant Studio 3 machine (Applied Biosystems). The primers used were $C c l 2$ (Mm00441242_m1), Tnfa (Mm00443258_m1), Illb (Mm00434228_m1), Il6 (Mm00446190_m1), and $\beta$ actin (Mm00607939_s1). Fold change was calculated using the $2^{-\Delta(\Delta \mathrm{Ct})}$ method compared with young or young wildtype control samples, unless otherwise stated.

\section{Protein Analysis}

Hepatocyte protein lysates were quantified using a BCA Assay (ThermoFisher Scientific). CCL2 was measured with the murine JE/MCP-1 (CCL2) enzyme-linked immunosorbent assay kit (Peprotech, Rocky Hill, NJ), according to the manufacturer's directions. 


\section{Flow Cytometry Experiments}

NPCs were washed in fluorescence-activated cell sorting buffer [5\% fetal bovine serum and 1\% bovine serum albumin in Hank's Buffered Saline Solution (Sigma-Aldrich)] and stained with fixable near-infrared viability dye $(1: 1000$; FisherScientific). Cells were blocked with Fc blocker (1:100; CD16/32; BD Biosciences), then surface stained with flow antibodies [1:20; F4/80-PE (BM8; eBioscience, ThermoFisher Scientific), CD11b-APC (1:20; M1/70; eBioscience, ThermoFisher Scientific), CD146-PerCypCy5.5 (1:20; ME9F1; BD Biosciences), and CD45-FITC (1:20; 30-F11; BD Biosciences)] for 20 minutes at $4^{\circ} \mathrm{C}$. Cells were fixed with Fixation Buffer (BioLegend) and stored overnight in fluorescence-activated cell sorting buffer. The following morning, cells were permeabilized with Intracellular Staining Permeabilization Wash Buffer (BioLegend) and stained with CD68-BV421 (1:20; FA-11; BioLegend). Cells were washed and analyzed on the MACSQuant Flow Cytometer (Miltenyi Biotec) and analyzed with FlowJo Software version 9.9.5 (FlowJo LLC, Ashland OR).

\section{Isolation and Maturation of Bone Marrow-Derived Macrophages}

Bone marrow was harvested from 2-month-old female WT mice (NIA) as follows. First, the harvested tibia and femur bones were rinsed in a sterile dish containing macrophage complete medium consisting of Dulbecco's modified Eagle's medium (Gibco, Grand Island, NY), 10\% fetal bovine serum (Invitrogen, Carlsbad, CA), 10\% L929 supernatant, $0.1 \% \beta$-mercaptoethanol (Gibco), $100 \mathrm{U} / \mathrm{mL}$ penicillin, 100 $\mu \mathrm{g} / \mathrm{mL}$ streptomyocin, $10 \mathrm{~mm}$ nonessential amino acids (Gibco), and $10 \mathrm{mmol} / \mathrm{L}$ HEPES buffer. Then, the ends of each bone were cut and the marrow cavity was flushed with the medium using a 30-gauge needle. The cells were plated at $10^{6} \mathrm{cell} / \mathrm{mL}$, and allowed to differentiate into macrophages for 7 days at $37^{\circ} \mathrm{C}, 5 \% \mathrm{CO}_{2}$, with complete media changes every 48 hours.

\section{Macrophage Cell Culture Experiments}

Isolated bone marrow macrophages or $\mathrm{F} 4 / 80^{+}$hepatic macrophages were cultured at 100,000 cells in a tissue culture-treated 96-well plate (Corning; $31.6 \mathrm{~mm}^{2}$ growth volume or 3165 cells $/ \mathrm{mm}^{2}$ ) in RPMI 1640 media (SigmaAldrich) supplemented with $10 \%$ fetal bovine serum (Corning), $1 \% 1 \mathrm{~mol} / \mathrm{L}$ HEPES (Sigma-Aldrich), and $1 \%$ penicillinstreptomycin (Fisher Scientific). After allowing hepatic macrophages to adhere to the cell culture plates for 3 hours, medium was replaced with fresh warmed medium (M0 group) or fresh medium supplemented with recombinant murine interferon- $\gamma(20 \mathrm{ng} / \mathrm{mL}$; Peprotech) and lipopolysaccharides from Escherichia coli O55:B5 (100 ng/mL; Sigma-Aldrich; M1 group), or supplemented with IL-4 (20 ng/mL; Peprotech; M2 group) for 12 hours. After 12 hours, the supernatants were collected for nitric oxide production assay using the Griess test. Briefly, supernatant was mixed with equal amounts of $1 \%$ sulfanilamide in 5\% phosphoric acid and $0.1 \% \mathrm{~N}$-(1-napthyl) ethylenediamine dihydrochloride (Sigma-Aldrich) and absorbance was read at $540 \mathrm{~nm}$ on Synergy HTX plate reader (BioTek, Winooski VT), compared with a standard curve prepared from $0.1 \mathrm{~mol} / \mathrm{L}$ sodium nitrite (Sigma-Aldrich). Cells were fixed with $2 \%$ paraformaldehyde, then blocked with 5\% donkey serum (ThermoFisher Scientific), $1 \%$ bovine serum albumin (Sigma-Aldrich), and $0.01 \%$ Triton X-Tween 20 (Fisher Scientific) for 1 hour for immunostaining. Primary antibodies, rabbit anti-mouse inducible nitric oxide synthase (1:100; ab3523; Abcam) and rabbit anti-mouse liver arginase (1:400; ab91279; Abcam), were applied to cells overnight at $4^{\circ} \mathrm{C}$. Cells were washed three times in PBS, then secondary antibodies were applied for 1 hour at 1:250 dilution (donkey anti-rabbit 488; ThermoFisher Scientific), counterstained with DAPI (BioLegend), and imaged. Alternatively, cells were incubated with Vybrant Phagocytosis FITC-E. coli particles (ThermoFisher Scientific) at a 1:20 dilution in media for 2 hours at $37^{\circ} \mathrm{C}$, then washed, fixed with $2 \%$ paraformaldehyde, and counterstained with DAPI for analysis of phagocytosis. Urea production was measured by lysing cells in $0.001 \%$ Triton-X (ThermoFisher Scientific) and combining with arginase activation solution $\left(10 \mathrm{mmol} / \mathrm{L} \mathrm{MnCl}_{2}\right.$ and $50 \mathrm{mmol} / \mathrm{L}$ Tris-HCl; Sigma-Aldrich) for 10 minutes at $56^{\circ} \mathrm{C}$, then incubating at $37^{\circ} \mathrm{C}$ for 22 hours with arginase substrate solution ( $0.5 \mathrm{~mol} / \mathrm{L}$ L-arginine; Sigma-Aldrich). Urea was measured with detection solution $(513 \mathrm{mg} / \mathrm{L}$ primaquine, $100 \mathrm{mg} / \mathrm{L}$ phthalaldehyde, $2.5 \mathrm{~mol} / \mathrm{L}$ sulfuric acid, $2.5 \mathrm{~g} / \mathrm{L}$ boric acid, and $0.03 \%$ Brij35; Sigma-Aldrich) against a urea standard curve, and absorbance was read at $430 \mathrm{~nm}$ on Synergy HTX plate reader.

\section{Endotoxin Assay and 16S rRNA from Hepatic Blood}

Blood was collected from female 3-month-old and 19month-old (NIA) mice fasted for 6 hours sterilely by inserting a catheter directly into the inferior vena cava. Blood was allowed to coagulate in a sterile tube for 15 minutes and centrifuged at $10,000 \times g$ for 10 minutes, and the serum supernatant was collected and stored at $-80^{\circ} \mathrm{C}$. Serum was diluted 1:10, and levels of endotoxin were quantified using the ToxinSensor LAL Chromogenic Endotoxin Quantitation Kit (VWR, Radnor, PA), according to the manufacturer's instructions. Alternatively, blood was collected in EDTA tubes (BD Biosciences), then DNA was isolated using the DNeasy Blood and Tissue Kit (Qiagen). Quantitative RT-PCR was performed on DNA for 16S rRNA (TaqMan: Ba04930791_s1), according to methods described in Gene Expression.

\section{RNA-Seq and Pathway Analysis}

RNA was processed by the University of Pittsburgh Health Sciences Sequencing Core for mRNA-sequencing (Seq). Libraries were prepared with TruSeq Stranded mRNA kit 
Table 1 Body Weight, Liver Biochemistry, and Serum Lipids in Young and Aged Mice

\begin{tabular}{lllr}
\hline & $\begin{array}{l}\text { Young NIA mice } \\
\text { (aged 3 months) } \\
(n=5-7)\end{array}$ & $\begin{array}{l}\text { Aged NIA mice } \\
\text { (aged 19 months) } \\
(n=5-6)\end{array}$ & $\begin{array}{l}P \text { value } \\
\text { Characteristic }\end{array}$ \\
\hline Body weight, g & $22.0 \pm 1.4$ & $1.33 \pm 0.2$ & $<0.01$ \\
Liver weight, g & $1.04 \pm 0.2$ & $4.98 \pm 0.4$ & $<0.05$ \\
Liver/body weight ratio & $4.72 \pm 0.9$ & $45.3 \pm 24$ & 0.62 \\
Alanine transaminase, IU/L & $23.0 \pm 5.5$ & $62.0 \pm 27$ & $<0.01$ \\
Aspartate transaminase, IU/L & $40.3 \pm 7.6$ & $0.17 \pm 0.1$ & 0.05 \\
Serum bilirubin, $\mathrm{mg} / \mathrm{dL}$ & $0.21 \pm 0.1$ & $2.48 \pm 0.2$ & 0.22 \\
Serum albumin, g/dL & $2.50 \pm 0.3$ & $78.8 \pm 28$ & 0.78 \\
Serum cholesterol, $\mathrm{mg} / \mathrm{dL}$ & $59.6 \pm 11$ & $66.7 \pm 20$ & 0.05 \\
Serum triglycerides, $\mathrm{mg} / \mathrm{dL}$ & $69.6 \pm 28$ & & 0.88 \\
\hline
\end{tabular}

NIA, National Institute on Aging.

(Illumina, San Diego, CA), according to manufacturer's instructions. Sequencing was on a NextSeq 500 (Illumina) using a single mid-output flow cell and 150-base single read. Adapter sequences were trimmed during demultiplexing. This project used the Pittsburgh Health Sciences Core Research Facility Genomics Research Core for RNA sequencing experiments.

Raw data were processed in CLC Genomics Workbench 11 (Qiagen). Reads were mapped to the mouse reference genome; and differentially expressed genes were determined between young and aged hepatocyte samples using filters to select genes with reads per kilobase of transcript per million $\geq 1$, absolute fold change $>1.5$, and false discovery rate $\leq 0.05$. Differentially expressed genes were imported into Ingenuity Pathway Analysis version 01-12 (Qiagen) to determine signaling pathways and upstream regulators. Activation (positive $\mathrm{z}$ score), inhibition (negative $\mathrm{z}$ score), and interactions of canonical pathways were examined on the basis of experimentally determined gene expression changes reported in the literature. Gene fold changes were also uploaded into the BaseSpace Correlation Engine, formerly NextBio, a searchable, online database from Illumina. Pairwise correlation scores were assigned between all gene expression signatures in the database using rank-based enrichment statistics. The most correlated gene expression studies were assigned a numerical score of 100 , and the remaining results are normalized to the top-ranked study.

\section{Statistical Analysis}

When comparing young and aged samples (WT or KO), a two-tailed $t$-test was used, unless otherwise stated. One-way analysis of variance was used to compare polarization of macrophages, with Tukey multiple comparisons, unless otherwise stated. Two-way analysis of variance was used to detect differences in the proportions of CD11b and CD68 populations between young and aged mice, with Sidak multiple comparisons test. $P \leq 0.05$ was considered significant.

\section{Results}

\section{Aged Mice Have Increased Body Weight, Increased Liver Weight, and Elevated Serum ALT Levels}

Aged virgin female mice (19 months old) obtained from the NIA animal repository showed a 1.3-fold increase in total body weight and liver weight compared with young female mice (3 months old) (Table 1). The liver/body weight ratio remained proportional between the age groups $(4.7 \%$ to $5.0 \%$ total body weight). To evaluate hepatic injury and function, serum levels of ALT, AST, bilirubin, and albumin were measured in the aging female mice (Table 1). There were slight, but significant, increases in serum ALT and AST, whereas serum albumin and bilirubin were unchanged. Likewise, serum cholesterol was increased significantly, whereas serum triglyceride levels were unchanged. The elevated liver enzymes in the 19-month-old mice suggest mild hepatocyte damage or stress in the absence of experimental injury or manipulation.

\section{Aged Livers Show Signs of Steatosis in the Absence of Injury}

Macroscopically, livers from 19-month-old mice appear similar to those from 3-month-old mice, with no evidence of gross tumor, fibrosis, or cirrhosis, although aged livers are larger with slight pallor (Figure 1A). Microscopically, the aged livers showed modest microvesicular steatosis both by Oil Red $\mathrm{O}$ and hematoxylin and eosin staining (Figure 1B). Terminal deoxynucleotidyl transferasemediated dUTP nick-end labeling staining showed minimal apoptotic hepatocytes or NPCs, and picrosirius red staining also showed lack of fibrosis in either young or aged liver samples (Supplemental Figure S1).

To further investigate the lipid content in the aged livers, the amount of total cholesterol and triglycerides was measured in mice fasted for 6 hours (to control for dietary intake). Aged livers showed a significant, 1.9-fold increase in triglyceride content and a significant, 1.5-fold increase in 

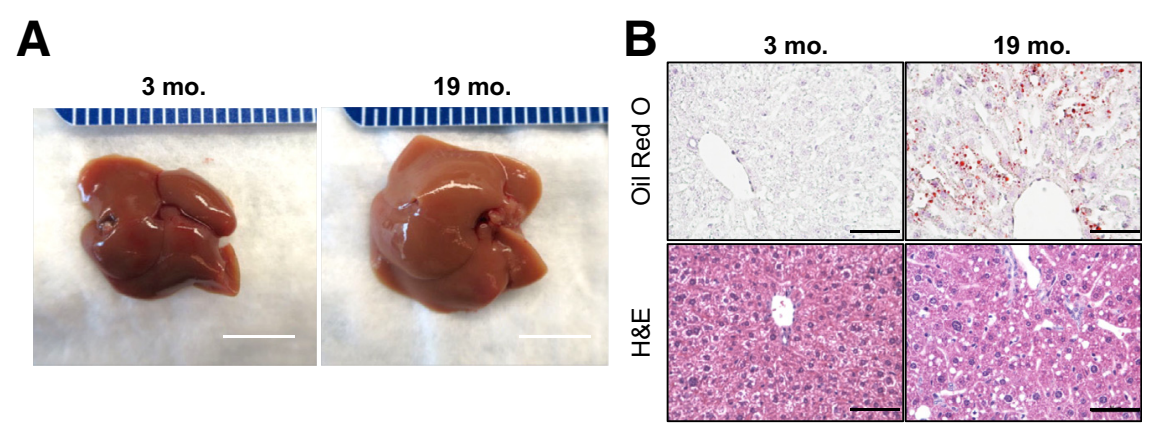

C
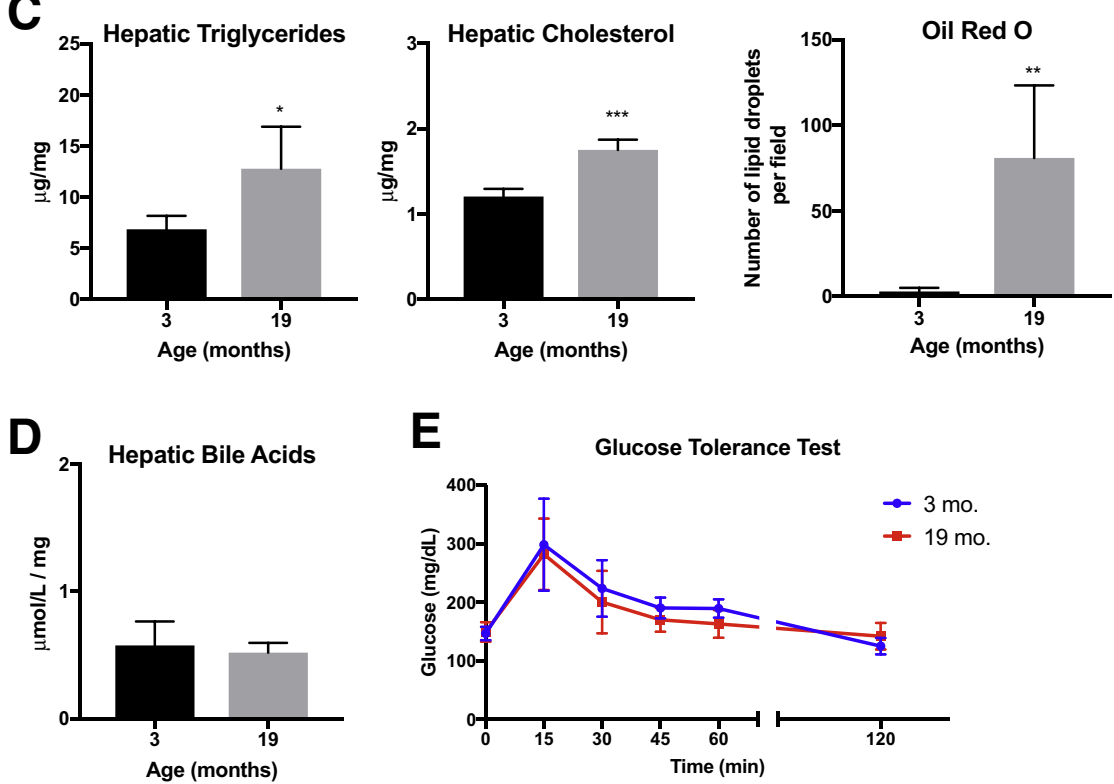

E

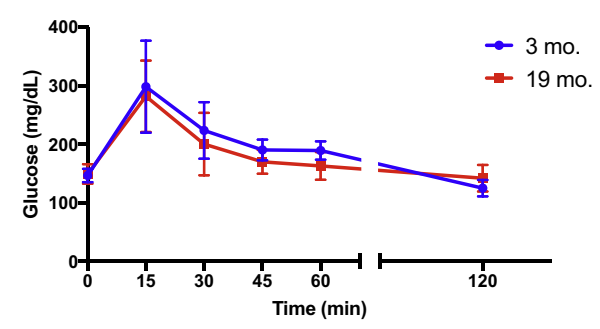

Figure 1 Aged livers exhibit signs of steatosis. A: Representative images of 3-month-old and 19month-old livers. B: Representative images of Oil Red 0 and hematoxylin and eosin (H\&E) staining demonstrate an increase in hepatic lipids in 19month-old livers. C: Quantification of hepatic triglycerides and cholesterol per milligram of liver tissue. D: Quantification of total hepatic bile acids. E: Glucose tolerance test shows no change in fasting glucose levels or blood glucose over time. Data are expressed as means \pm SD (C-E). $n=4$ to 5 (B); $n=4(\mathbf{C}$ and $\mathbf{E}) ; n=3$ (D). ${ }^{*} P<0.05,{ }^{*} P<0.01$, and $* * * P<0.001$ versus 3 months old. Scale bars: 1 $\mathrm{cm}($ A); $50 \mu \mathrm{m}$ (B). cholesterol content per milligram of liver tissue when compared with the young livers (Figure 1C). The types of fatty acids composing the triglycerides and their relative proportions were unchanged between the age groups, with the exception of a significant decrease in myristic acid (14:0) in the livers from aged mice (Supplemental Table S1). In addition, the concentration of total bile acids in the livers was similar between the two age groups, suggesting no deficits in bile acid production and metabolism or signs of cholestasis (Figure 1D).

To assess the potential confounding effects of metabolic syndrome on lipid storage in the liver, an i.p. glucose tolerance test was performed on the 3-month-old and 19month-old mice after fasting for 6 hours. Basal glucose concentrations were similar between the age groups, and both groups metabolized glucose comparably, suggesting preserved glucose tolerance (Figure 1E). In addition, hepatic nuclear localization of cyclin-dependent kinase inhibitor p21, a marker of cellular senescence, ${ }^{24}$ was analyzed, and no changes were observed from 3 to 19 months of age (Supplemental Figure S2). Overall, these studies demonstrate hepatic steatosis in the aged mice without notable differences in bile acid, glucose homeostasis, or cell cycle arrest.
Aged Livers Show Signs of Spontaneous Inflammation in the Absence of Injury

The livers from aging mice were assessed for evidence of inflammation. Whole liver tissue and hepatocytes were isolated from the 3-month-old and 19-month-old mice. Quantitative RT-PCR showed an increase in $C c l 2$ expression in aged whole liver samples (threefold) and aged hepatocytes (10-fold) (Figure 2A). Enzyme-linked immunosorbent assay confirmed increases of protein levels of CCL2 (3.6-fold) from aged hepatocyte fraction lysates (Figure 2B). Additional inflammatory genes were up-regulated in the aged samples, including Tnf, Illb, and Il6 (Figure 2C). Taken together, increased cytokine production was detected in the aged liver hepatocyte cell fractions at both the RNA and protein levels.

\section{Macrophages Increase in the Aged Liver and Retain Polarization and Phagocytic Capacity in Vitro}

The observed increase of chemokine CCL2 levels prompted further investigation of the hepatic macrophage content of aging mice. Flow cytometry of the NPC fraction revealed a significant increase in $\mathrm{F} 4 / 80^{+}$macrophages in the livers from aged mice (Figure 3A), which was confirmed by 


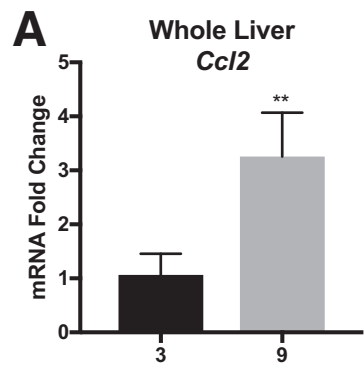

Age (months)
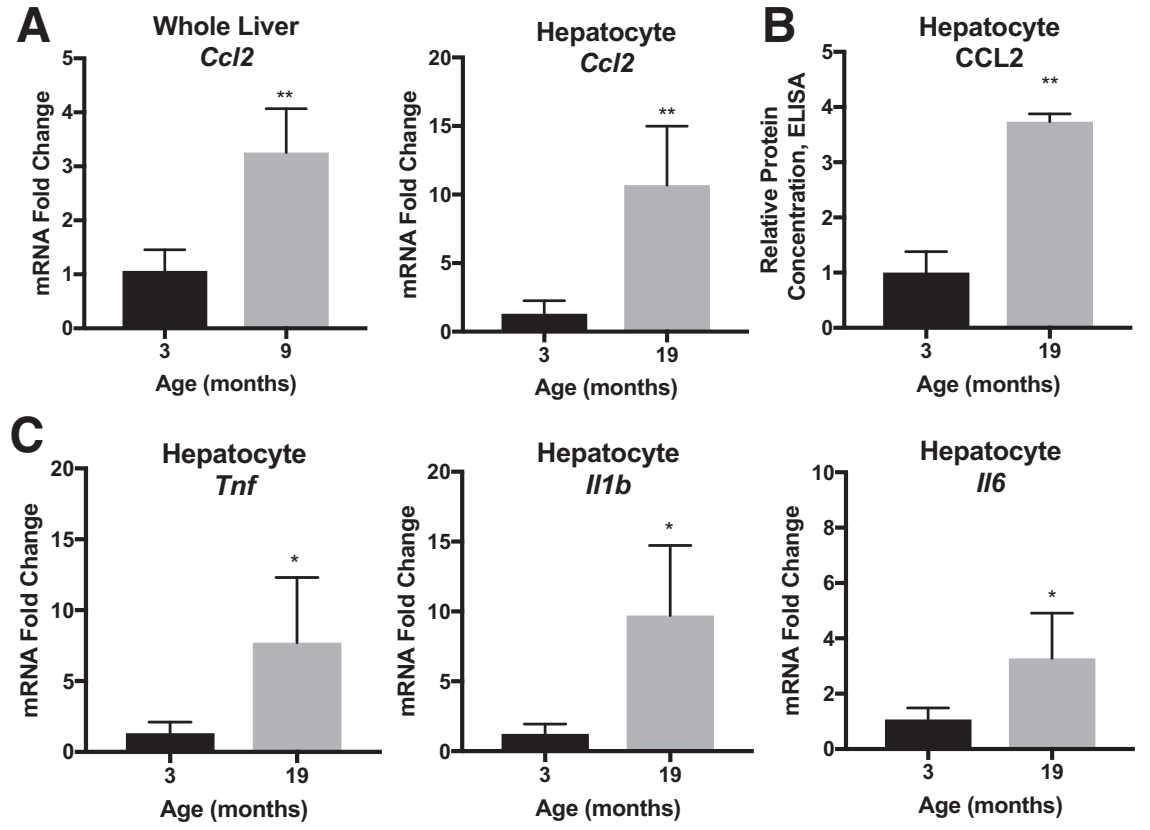

Figure 2 Aged livers have robust inflammatory signatures. A: Significant increase in mRNA levels of chemokine ( $\mathrm{C}-\mathrm{C}$ motif) ligand (CCL) 2 are detected in 19-month-old whole livers and hepatocytes, normalized to $\beta$-actin housekeeping gene and 3-month-old controls. B: Enzyme-linked immunosorbent assay (ELISA) for CCL2 in hepatocyte protein lysates, normalized to 3-month-old controls. C: Significant increases in mRNA levels of tumor necrosis factor (TNF), IL-1 $\beta$, and IL-6, are detected in 19-month-old hepatocyte cell fractions, normalized to $\beta$-actin housekeeping gene and 3-month-old controls. Data are expressed as means $\pm \mathrm{SD}(\mathbf{A}-\mathbf{C}) . n=3$ to $4(\mathbf{A}) ; n=3(\mathbf{B}) ; n=$ $6(\mathrm{C}) .{ }^{*} P<0.05,{ }^{*} P<0.01$ versus 3 months old. histologic staining (Figure 3B). A time course of $\mathrm{F} 4 / 80^{+}$ cell content showed stable levels of hepatic macrophages at 3,7 , and 15 months of age, a significant increase at 19 months of age, and further elevation at 24 months of age ( \pm 1 month) (Supplemental Figure S3). Levels of F4/80 cells in 19-month-old mice were not statistically different from 15-month-old mice but were significantly different from the 3-month-old mice. By 24 months of age, most livers developed either spontaneous tumors or extensive NASH and were thus excluded from further investigation as part of the current study.

The gene expression profile of freshly isolated $\mathrm{F} 4 / 80^{+}$ hepatic macrophages from 3-month-old to 19-month-old mice was compared (Figure 3C). All fold changes were modest, and there were no significant differences between the young and aged hepatic macrophages. However, the genes Il6, Tnf, and Ccl 2 decreased in aged $\mathrm{F} 4 / 80^{+}$cells compared with young, the opposite trend from the aged hepatocyte fraction. $I l 1 b$ trended upwards in the aged macrophages, similarly to the aged hepatocyte fractions. Nos2, the gene that encodes inducible nitric oxide synthase, a marker of M1 proinflammatory cell activation, was similarly expressed between the young and aged macrophages, whereas the genes Arg1 and Chil3, markers of M2 alternative activation, were slightly increased in the aged macrophages.

To further assess aged hepatic macrophage phenotype, cells were placed in culture for 18 hours and levels of nitrite (M1 activation) and urea (M2 activation) were measured in the supernatants. At baseline, macrophages from 19month-old mice secreted similar levels of nitrite as those from 3-month-old mice (Figure 3D). When treated with interferon- $\gamma$ and lipopolysaccharide to stimulate an M1 phenotype, the young hepatic macrophages had a sevenfold increase in nitric oxide secretion, whereas the aged hepatic macrophages had a 25 -fold increase in nitric oxide secretion. Similarly, at baseline, macrophages from 19-month-old mice secreted similar levels of urea as those from 3month-old mice (Figure 3E). When treated with IL-4 to stimulate an M2 phenotype, both young and aged hepatic macrophages had a sixfold increase in urea secretion from baseline. In addition, the M1 and M2 stimulated hepatic macrophages from young and aged mice were able to effectively phagocytose FITC-labeled E. coli particles (Supplemental Figure S4A).

Finally, immunostaining for inducible nitric oxide synthase and arginase- 1 was performed after the polarization experiments. The young and aged hepatic macrophages had comparable levels of inducible nitric oxide synthase labeling (Figure 3F), which was overall dim when compared with bone marrow-derived macrophages treated similarly (Supplemental Figure S4B). The hepatic macrophages strongly expressed arginase, particularly in the aged group, which was significantly increased after treatment with IL-4 compared with macrophages from 3-month-old mice (Figure 3G).

Taken together, the aged hepatic macrophages responded more strongly to both the M1 and M2 polarizing cytokines but had greater M2 characteristics at baseline when compared with the young hepatic macrophages.

\section{Aged Livers Have Increased CD11 $\mathrm{b}^{+}$Macrophage Populations}

To further profile the aged hepatic macrophage compartment, expression levels of CD11b and CD68 were examined by 
A

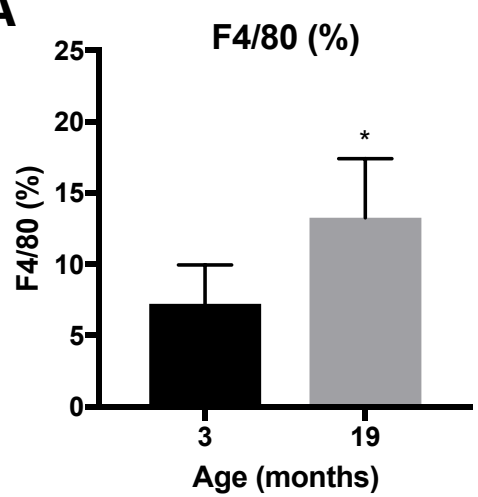

B

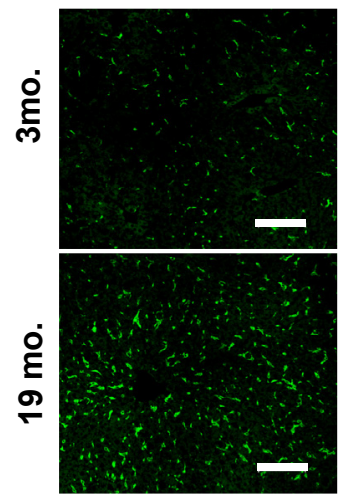

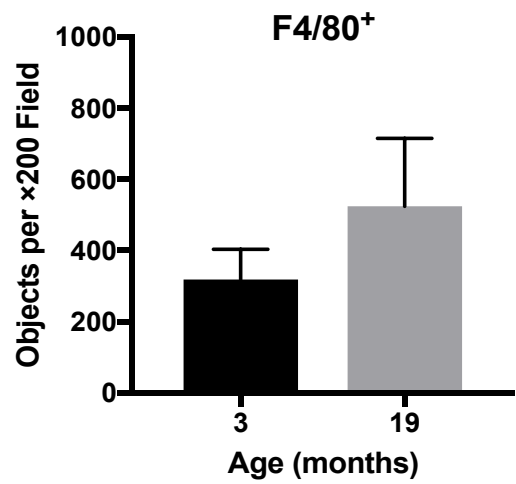
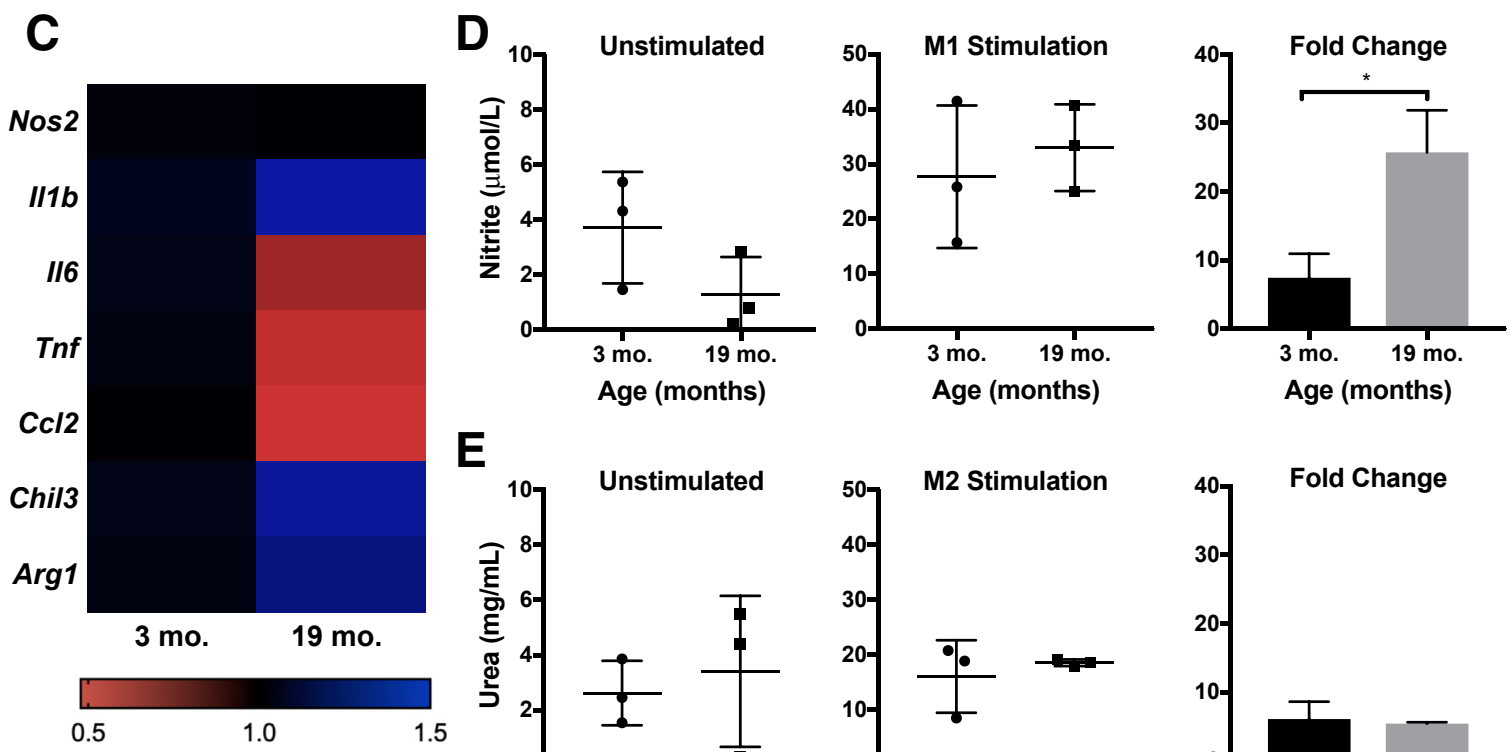

E
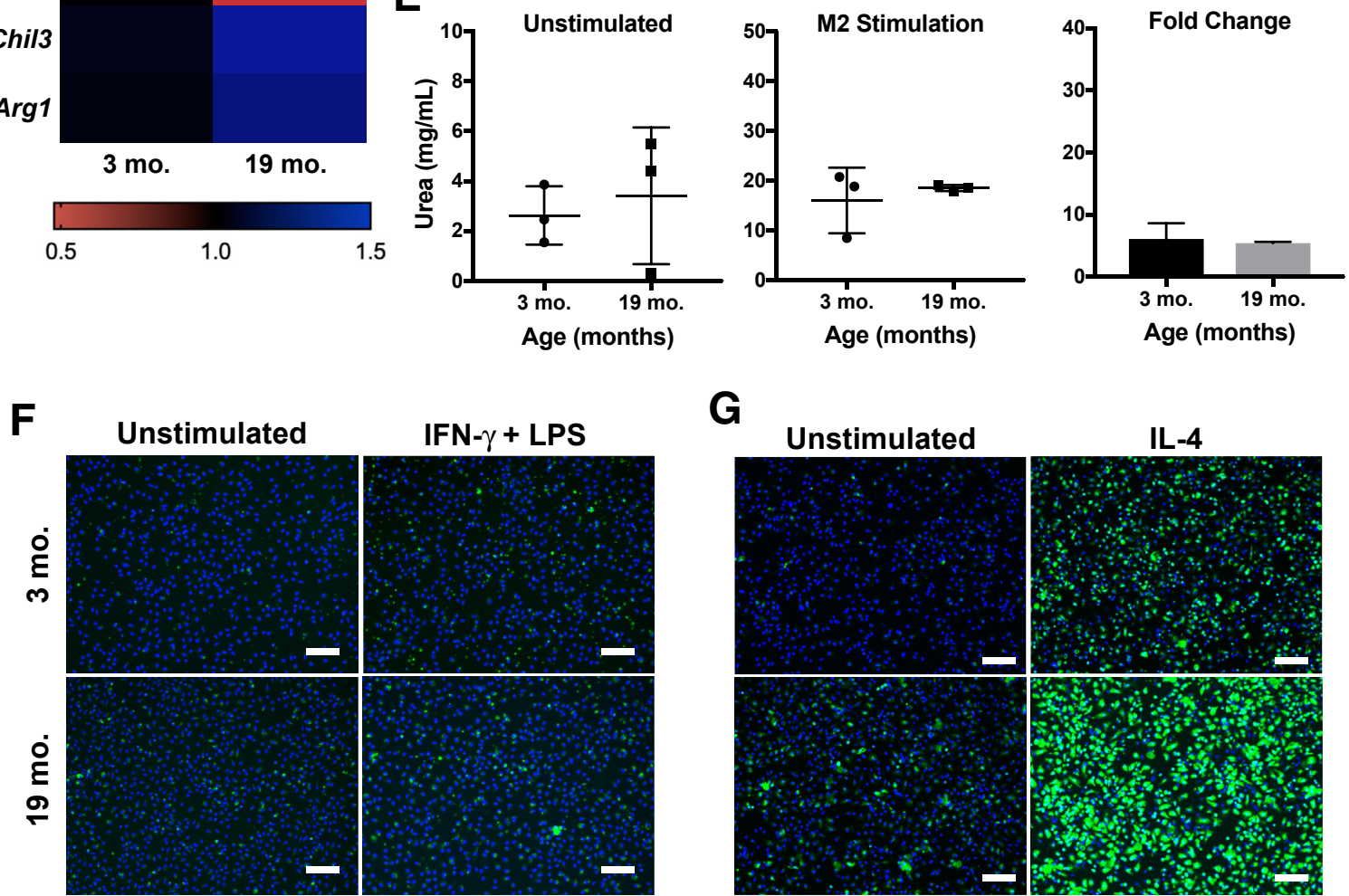

G

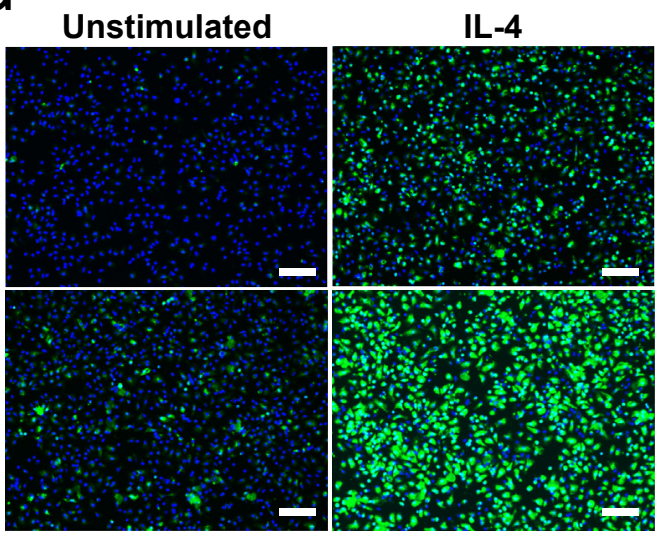

Figure 3 Macrophages accumulate in the uninjured, aged liver and are primed toward enhanced activation. A: Percentage of total $\mathrm{F} / 80^{+}$cells in the nonparenchymal cell fraction, determined by flow cytometry. Gating strategy is available in Supplemental Figure S2. B: Histologic immunostaining for F4/80 (green) further demonstrates increase in macrophages across 19 -month-old liver sections. C: Heat map displaying PCR results from $\mathrm{F} 4 / 80^{+}$cells isolated from 3month-old and 19-month-old livers at baseline (normalized to $\beta$-actin housekeeping gene; fold change versus young average). No statistical differences are detected. D: Nitrite measured in supernatant of hepatic macrophages cultured for 18 hours unstimulated or after treatment with $\mathrm{M} 1 \mathrm{stimulus}$ [20 ng/mL interferon (IFN) $-\gamma$ and $100 \mathrm{ng} / \mathrm{mL}$ lipopolysaccharide (LPS); normalized to DAPI nuclei counts; fold change versus unstimulated]. E: Urea levels from hepatic macrophages cultured for 18 hours unstimulated or after treatment with M2 stimulus ( $20 \mathrm{ng} / \mathrm{mL}$ IL-4; normalized to DAPI nuclei counts; fold change versus unstimulated). $\mathbf{F}$ and G: Representative images of hepatic macrophages stained for inducible nitric oxide synthase $(\mathbf{F})$ or arginase- $1(\mathbf{G})$ at 18 hours after treatment. Data are expressed as means $\pm \mathrm{SD}(\mathbf{A}, \mathbf{B}, \mathbf{D}$, and $\mathbf{E}) . n=5(\mathbf{A}$ and $\mathbf{B}) ; n=3$ to $4(\mathbf{C}) ; n=3(\mathbf{D}$ and $\mathbf{E}) .{ }^{*} P<0.05$ versus 3 months old. Scale bars $=100 \mu \mathrm{m}(\mathbf{B}, \mathbf{F}$, and $\mathbf{G})$. 
A
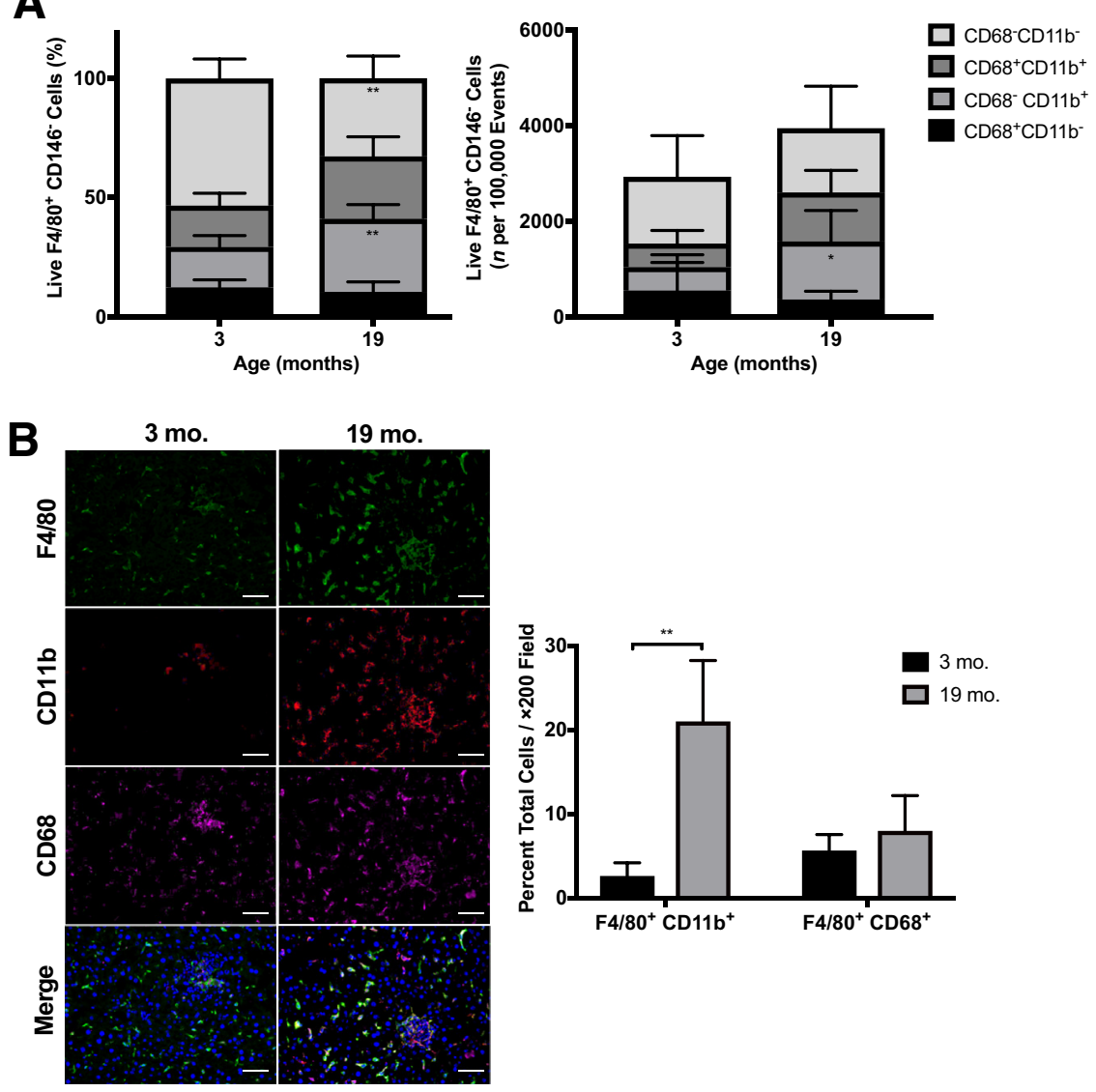

Figure 4 Macrophages in aged livers have increased $\mathrm{CD}_{11 \mathrm{~b}^{+}}$subsets. A: Proportion and number of CD11b- and CD68-expressing $\mathrm{F} 4 / 80^{+}$ cells detected by flow cytometry show an increase in $\mathrm{CD}_{11 \mathrm{~b}^{+}}$macrophages in 19-month-old livers. Gating strategy is available in Supplemental Figure S2. B: Increases in $\mathrm{F} 4 / 80^{+} \mathrm{CD}_{11 \mathrm{~b}^{+}}$macrophages are confirmed with histologic immunostaining. Data are expressed as means \pm SD (A and $\mathbf{B}) . n=5$ (A and $\mathbf{B}) .{ }^{*} P<0.05,{ }^{*} * P<0.01$ versus 3 months old. Scale bar $=50 \mu \mathrm{m}$ (B). flow cytometry, as these markers have been used as indicators of macrophage origin from bone marrow or tissue, respectively. ${ }^{17,25}$ Livers from 19-month-old mice had a significant increase in the $\mathrm{CD}^{-} 8^{-} \mathrm{CD} 11 \mathrm{~b}^{+}$monocyte-derived population, in both percentage and absolute number of $\mathrm{F} 4 / 80^{+}$cells (Figure 4A and Supplemental Figure S3). No change was observed in the $\mathrm{CD}^{+} 8^{+} \mathrm{CD} 11 \mathrm{~b}^{-}$population, reported by others to be Kupffer cells, whereas there was a marginal but insignificant increase in the $\mathrm{CD}^{+} 8^{+} \mathrm{CD} 11 \mathrm{~b}^{+}$population. The increase in $\mathrm{F} 4 / 80^{+} \mathrm{CD} 11 \mathrm{~b}^{+}$macrophages, but not $\mathrm{F} 4 /$ $80^{+} \mathrm{CD} 8^{+}$Kupffer cells, in livers from aged mice was also confirmed by histologic staining (Figure 4B). These data suggest that the increase in hepatic macrophages in aged mice is derived primarily from infiltrating monocytes and not due to an expanding resident Kupffer cell population, consistent with the detected increase in monocyte chemoattractant protein (CCL2) and the observations of others in steatosis models. $^{19}$

\section{CCL2-CCR2 Inhibition Reduces Inflammation and Steatosis in Aged Livers, but Does Not Prevent Accumulation of $\mathrm{CD}_{11} \mathrm{~b}^{+}$Macrophages}

To test the hypothesis that inhibiting CCL2 signaling would reduce inflammation and steatosis in aging livers, female mice with global CCR2 KO or WT controls were obtained from Jackson Laboratories as retired breeders and aged in house. The aged WT mice had a significant, 1.6-fold increase in body weight compared with their young controls, whereas the aged KO mice had a significant, 1.2-fold increase in body weight compared with their young controls (Table 2). In addition, the aged KO mice had elevated serum cholesterol levels compared with the young $\mathrm{KO}$ mice. Levels of serum ALT, AST, albumin, and triglycerides were similar between the groups.

Of note, three mice in the aged WT cohort were excluded from study: one showed advanced fatty liver disease with hepatocyte ballooning characteristic of NASH, another had extensive tumorigenesis, and one died prematurely (Supplemental Figure S5). No mice in the aged KO group exhibited these pathologic signs. Both 19-month-old WT and KO cohorts had increased lipid accumulation compared with their respective 3-month-old controls qualitatively, as shown by hematoxylin and eosin and Oil Red $\mathrm{O}$ staining; however, there were no statistical differences, and large variation was not noted in the aged WT mice (Figure 5A).

The concentration of hepatic lipids was measured in the 3-month-old and 19-month-old WT and KO mice after 6 hours of fasting. The 19-month-old WT mice had a significant, 1.5-fold increase in the triglyceride content compared with the 3-month-old WT mice, whereas the KO groups were not significantly different (Figure 5B). No differences in cholesterol content were detected between the 
Table 2 Body Weight, Liver Biochemistry, and Serum Lipids in Young and Aged CCR2 K0 Mice

\begin{tabular}{|c|c|c|c|c|c|c|}
\hline Characteristic & $\begin{array}{l}\text { Young WT mice } \\
\text { (aged } 3 \text { months) } \\
(n=5)\end{array}$ & $\begin{array}{l}\text { Aged WT mice } \\
\text { (aged } 19 \text { months) } \\
(n=8)\end{array}$ & $\begin{array}{l}P \text { value for young } \\
\text { vs aged WT mice }\end{array}$ & $\begin{array}{l}\text { Young KO mice } \\
\text { (aged } 3 \text { months) } \\
(n=4)\end{array}$ & $\begin{array}{l}\text { Aged K0 mice } \\
\text { (aged } 19 \text { months) } \\
(n=10)\end{array}$ & $\begin{array}{l}P \text { value for } \\
\text { young vs } \\
\text { aged K0 mice }\end{array}$ \\
\hline Serum ALT, IU/L & $21.2 \pm 8.4$ & $31.8 \pm 10$ & 0.09 & $24.5 \pm 10$ & $23.3 \pm 5.6$ & 0.77 \\
\hline Serum AST, IU/L & $43.8 \pm 10$ & $55.1 \pm 22$ & 0.31 & $46.0 \pm 18$ & $48.6 \pm 13$ & 0.77 \\
\hline Serum albumin, g/dL & $2.68 \pm 0.2$ & $2.47 \pm 0.1$ & 0.17 & $2.47 \pm 0.1$ & $2.50 \pm 0.1$ & 0.72 \\
\hline
\end{tabular}

ALT, alanine transaminase; AST, aspartate transaminase; KO, knockout; WT, wild type.

young and aged groups in both the WT and KO mice (data not shown).

The inflammatory gene signature of hepatocyte cell fractions isolated from 3-month-old and 19-month-old WT and KO mice was evaluated by quantitative RT-PCR. The 19-month-old WT cells had a significant increase in $I l l b$, Il6, Tnf, and Ccl2 transcripts compared with the 3month-old WT group, whereas there were no changes in inflammatory gene expression between the 3-month-old and 19-month-old KOs (Figure 5C). Protein levels of CCL2 were also measured by enzyme-linked immunosorbent assay and showed a similar trend as the gene expression; however, CCL2 was not significantly elevated in the 19-month-old WT group compared with the 3month-old control group (Figure 5D).

Despite the reduction in the inflammatory gene signature by hepatocytes from aged CCR2 knockout mice, the levels of $\mathrm{F} 4 / 80^{+}$cells and specifically $\mathrm{F} 4 / 80^{+} \mathrm{CD} 11 \mathrm{~b}^{+}$macrophage subsets were elevated in both WT and KO 19month-old livers, compared with their 3-month-old counterparts, as determined by flow cytometry (Figure 5E). In addition, the number of $\mathrm{F} 4 / 80^{+}$cells increased in both cohorts from young to aged mice, demonstrating that the increase in percentage of macrophages was not due to a decrease in other NPC types. Taken together, these data suggest that inhibiting CCR2 signaling was sufficient to reduce hepatic triglyceride content and inflammatory gene expression but did not prevent the accumulation of CD11 $\mathrm{b}^{+}$ macrophages in the aging liver.

To determine if other $\mathrm{CCR} 2^{+}$cell populations were influenced by CCR2 knockout in livers from aged mice, immunostaining for CD3 $\mathrm{T}$ cells was performed. No differences were observed in the number of $\mathrm{CD}^{+}$cells throughout the liver parenchymal between young and aged WT and KO mice (data not shown). Because inhibiting CCL2-CCR2 was insufficient to prevent macrophage accumulation in aged livers, levels of endotoxin and bacterial DNA for 16s rRNA in hepatic blood were measured to test for leaky gut syndrome, as this has been implicated in promoting age-related inflammation. ${ }^{26}$ However, no differences were observed in serum endotoxin or 16s rRNA in hepatic blood (Supplemental Figure S6).
RNA-Seq Analysis Demonstrates Robust Inflammatory and Metabolic Changes in Aged Livers beyond the CCL2-CCR2 Signaling Paradigm

Finally, RNA-Seq was performed as an unbiased screen to further elucidate mechanisms underlying the onset of inflammation and steatosis in aged livers. Independent samples of hepatocytes ( $83 \%$ to $90 \%$ purity) were enriched from 3-month-old and 19-month-old wild-type mice (NIA; $n=$ 3 ) by two-step collagenase perfusion after fasting for 6 hours.

In total, 296 genes were differentially up-regulated, and 74 genes were differentially down-regulated, between the 3 month-old and 19-month-old samples (fold change \pm 2 ; false discovery rate $P<0.05$ ) (Figure 6A). Although an increase in the proliferation/ploidy gene E2f7 (9.5-fold) was detected, no changes were seen in senescence-associated genes $(p 16, p 21$, and $p 53)$.

The data were further filtered using Ingenuity Pathway Analysis to compare transcriptomic changes specifically in hepatocytes, and 29 differentially expressed genes were identified in the samples from young and aged mice (Figure 6B). The canonical pathways involved were identified to be melatonin degradation, dopamine degradation, and adherens junction signaling and remodeling, characteristic of fatty acid and xenobiotic metabolism. When the analysis was expanded to whole liver tissue, additional inflammatory signatures were revealed (Figure 6C), including increases in $I l 1 b, C c l 5$, colony stimulator factor receptors (Csflr and Csf3r), integrins (Itga4, Itgb3, Itga9, and Itgb2), vascular adhesion markers (Pecaml and Vcaml), and mannose receptor ( $\mathrm{MrCl}$; an M2 marker), possibly influenced by NPCs. A complete list of differentially expressed genes can be found in Supplemental Table S2.

Interestingly, when the pathways are viewed as interconnecting nodes, the inflammatory and metabolic changes are linked by suppression of farnesoid X receptor (FXR) and retinoid $\mathrm{X}$ receptor (RXR) signaling, suggesting this transcription factor family may be a master regulator of several age-related gene expression changes in the liver and warrants further study (Supplemental Figure S7). Furthermore, when gene expression fold changes were uploaded into BaseSpace Correlation Engine (Illumina), the data set was correlated 
A
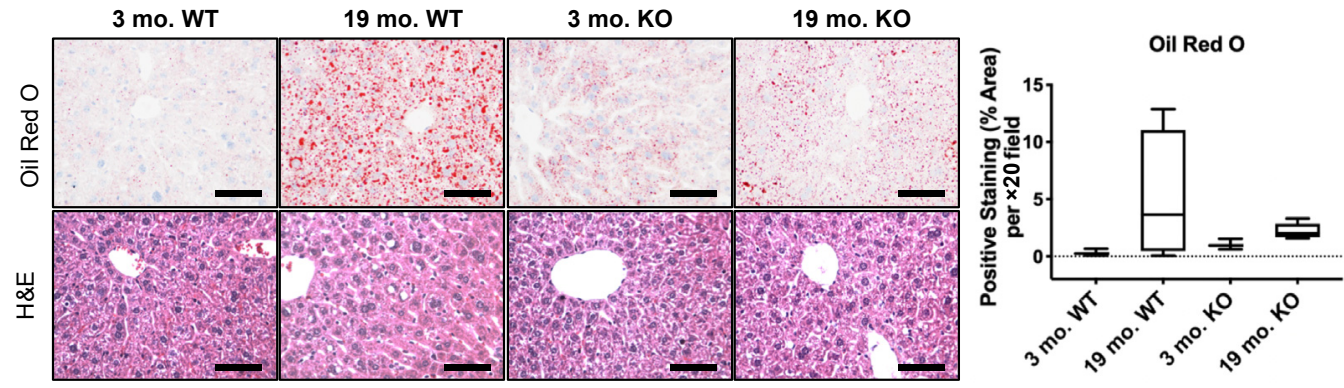

B

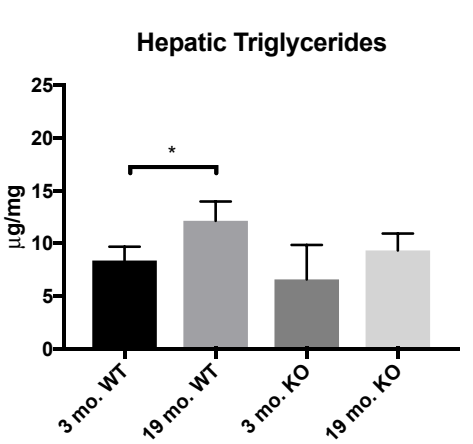

C
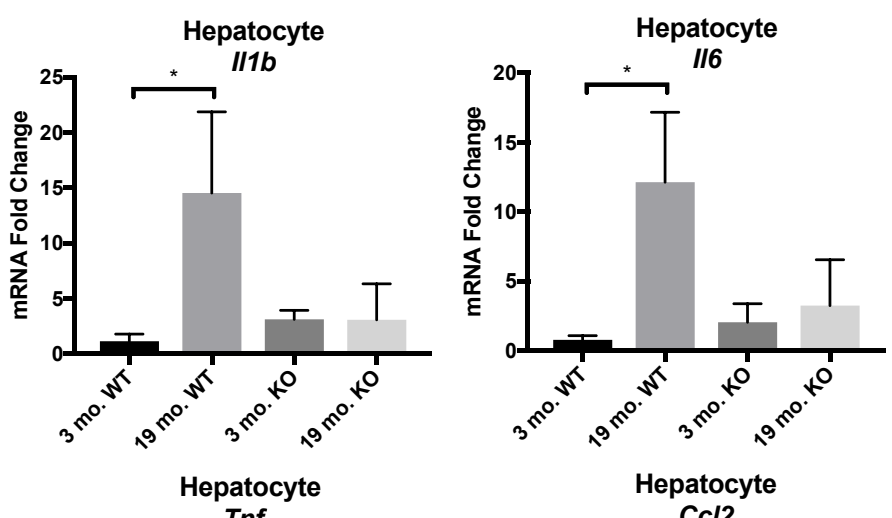

D

CCL2
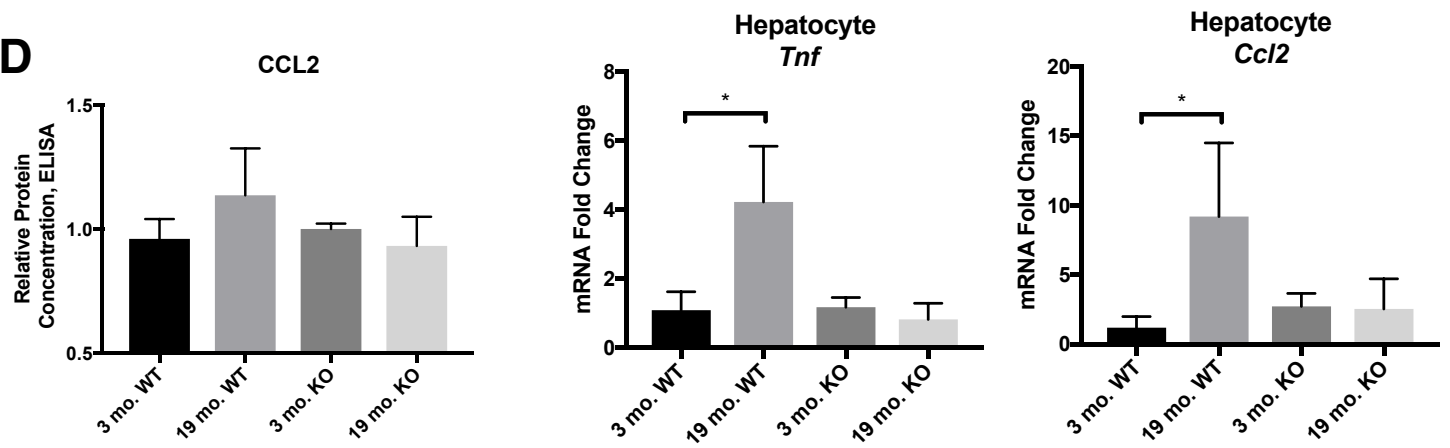

E
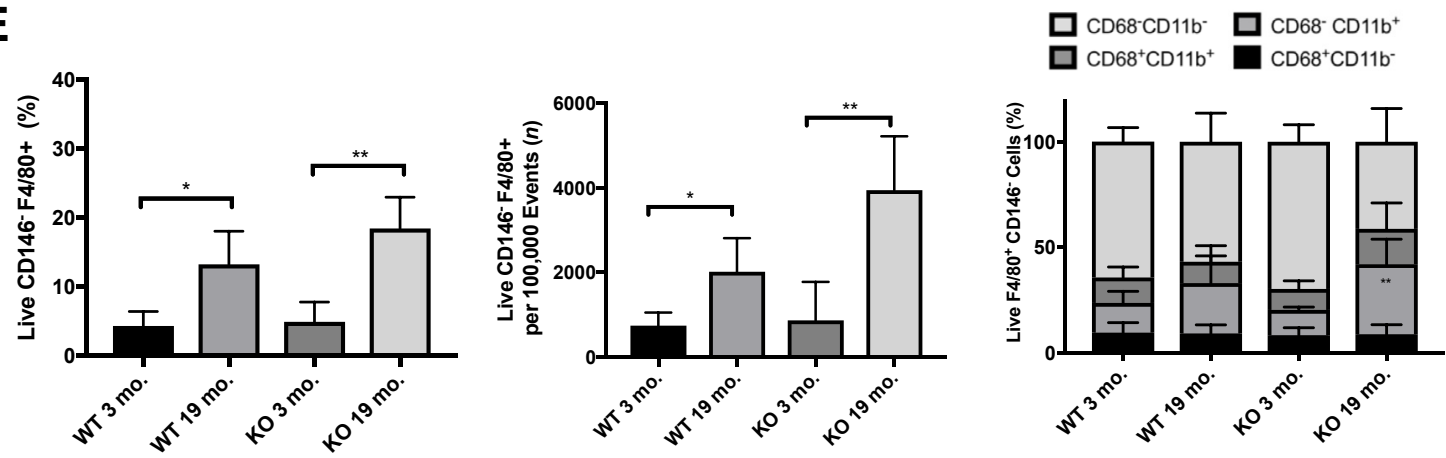

Figure 5 Aged CCR2 knockout mice exhibit reduced steatosis and inflammation, but no change in accumulated macrophage populations. A: Representative images of hematoxylin and eosin (H\&E) and 0il Red 0 staining and quantification $[P=0.2$ between wild type (WT) groups; $P=0.07$ between knockout (KO) groups; origin (dashed line) raised above $x$ axis to distinguish error bars]. B: Quantification of hepatic triglycerides per milligram of liver tissue. C: Significant increases in mRNA levels of IL-1 $\beta$, IL-6, tumor necrosis factor (TNF)- $\alpha$, and chemokine (C-C motif) ligand (CCL) 2 in aged WT compared with young WT, normalized to $\beta$-actin housekeeping gene. D: Enzyme-linked immunosorbent assay (ELISA) for CCL2 in hepatocyte protein lysates, normalized to WT 3month-old control. E: Percentage of total F4/80-, CD11b-, and CD68-expressing cells in the nonparenchymal cell fraction, determined by flow cytometry. Data are expressed as means \pm SD $(\mathbf{A}-\mathbf{E}) . n=4$ to $5(\mathbf{B}-\mathbf{E}) .{ }^{*} P<0.05,{ }^{*} P<0.01$ versus 3 months old. Scale bar $=50 \mu \mathrm{m}(\mathbf{A})$.

with studies from Wnt/ $\beta$-catenin knockout hepatocytes $(A p c$ or Ctnnbl knockouts; score, 100), aging in various organs on C57B1/6 background (score, 90), liver cells overexpressing yes-associated protein-1 (YAP; score, 90), livers from young and aged wild-type mice (score, 86), and livers from 12 different strains of mice fed a high-fat diet (score, 76), demonstrating a similar phenotype detected by others with aging, high-fat diet, and various genetic manipulations. 


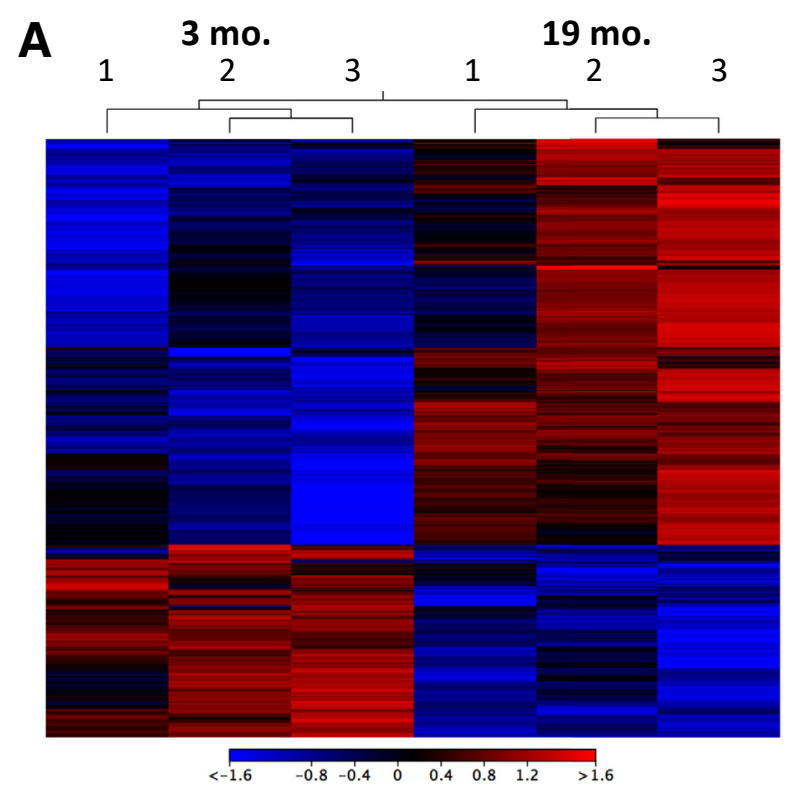

B
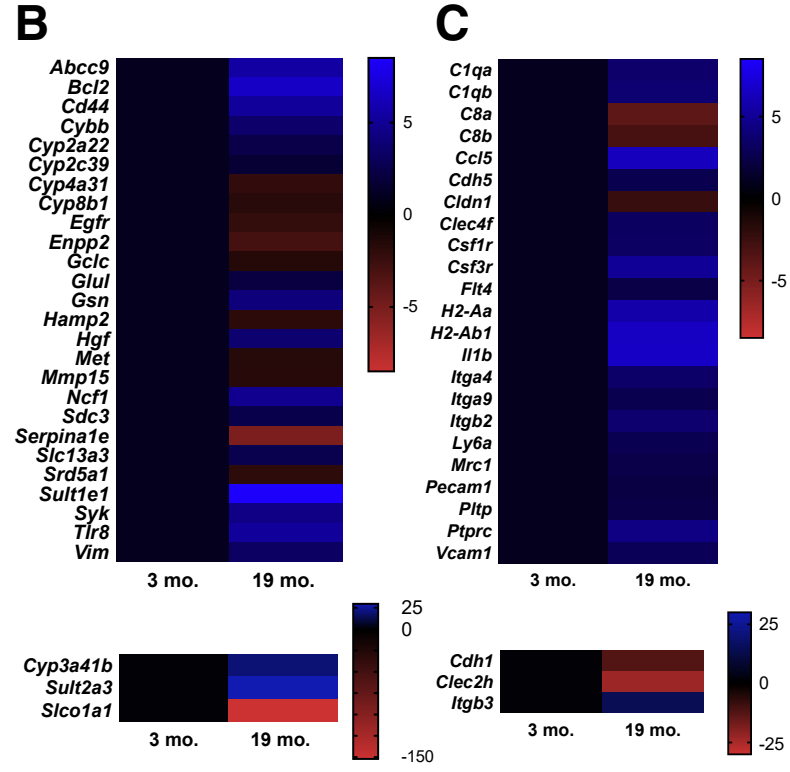

Figure 6 RNA sequencing reveals robust changes in inflammatory and metabolic gene signatures of aged livers. A: Heat map demonstrates 296 genes are differentially up-regulated and 74 genes are differentially downregulated between the 3-month-old and 19-month-old wild-type National Institute on Aging samples enriched for hepatocytes (fold change \pm 2 ; false discovery rate $P<0.05$ ). B: Heat map of filtered data in Ingenuity Pathway Analysis displays 29 differentially expressed hepatocyte-specific genes. C: Heat map displays filtered data in Ingenuity Pathway Analysis, demonstrating a selection of liver-specific differentially expressed inflammatory genes. $n=3(\mathbf{A}-\mathbf{C})$.

\section{Discussion}

It is well established that body weight increases with age in mammals, as lipids move from s.c. to visceral and ectopic fat deposits in muscle, bone marrow, and the liver. ${ }^{27}$ This accumulation of fat is thought to reduce muscle strength, lead to insulin resistance, decrease energy expenditure in brown adipose tissue, and impair the function of bone marrow stem cells. ${ }^{28} \mathrm{~A}$ recent study showed that lipid removal rates in adipose tissue decrease with aging ${ }^{29}$; however, the molecular mechanisms coupling ectopic fat accumulation with aging remain largely unknown and the influence of ectopic fat accumulation on liver function with aging has not been thoroughly studied.

In the present study, 19-month-old female mice received from the NIA exhibited increased liver and body weight, serum alanine aminotransferase, hepatic triglycerides, inflammatory gene expression, and levels of $\mathrm{F} 4 / 80^{+} \mathrm{CD}_{11 \mathrm{~b}^{+}}$macrophages when compared with their 3-month-old counterparts. A recent study identified a similar increase in body weight, liver weight, AST, serum cholesterol and triglycerides, and hepatic lipids in 20-month-old rats compared with 3-month-old controls. ${ }^{30}$ The increase in hepatic lipids detected in the aged mice $(186 \%$ increase in triglycerides) mimics what has been observed in elderly individuals in the absence of insulin resistance. ${ }^{4}$

Importantly, the 19-month-old mice used in this study were compared directly with 3-month-old control mice that were obtained from the same vendor to accurately assess the effects of aging on liver characteristics. Although not studied directly, the wild-type 19-month-old mice from Jackson Laboratories (Table 2) had a greater body weight (13.7\% on average) and more advanced steatosis than the 19-month-old mice received from the NIA (Table 1), possibly due to differences in the diets between the two facilities (16\% versus $11 \%$ fat, respectively). In addition, the macrophage populations were stable within the two cohorts of young mice, as assessed by flow cytometry, but differed between the two cohorts of aged mice (Figure 4A and Figure 5E). These differences may also be related to changes in the microbiome, genomic drift, or past breeding status of the mice but were not the focus of the present study.

In humans, NAFLD has been described as sexually dimorphic. ${ }^{22}$ Estrogen potentiates hepatic inflammatory changes, protecting premenopausal women from NAFLD. ${ }^{31}$ As such, NAFLD is most commonly diagnosed in males or elderly women with metabolic comorbidities. ${ }^{32}$ Many previous studies in liver aging have been performed in male mice, which develop glucose intolerance, insulin resistance, steatosis, and senescence at significantly younger ages than females, ${ }^{5,22,33}$ making the inclusion of aged female mice into the literature particularly important. The results from our study support the observation that female mice develop steatosis later than males; however, a direct comparison was not performed and may be an important avenue of future study.

The temporal presentation of inflammation versus steatosis in liver pathology is largely dependent on the triggering stimulus. Sublethal lipid overload in hepatocytes driven by diet has recently been shown to drive inflammation by the release of extracellular vesicles containing miRNAs, chemokines, and damage signals. ${ }^{34}$ Conversely, the production of cytokines and adipokines has been shown 
to regulate fat metabolism. ${ }^{35}$ This study demonstrated an increase in inflammatory cytokines from the hepatocyte fraction with aging, likely contributing to the infiltration of macrophages. However, in aging as opposed to high-fat diet, the mechanisms of macrophage recruitment are not well understood. Removal of CCR2 attenuated inflammation and reduced steatosis in the aging liver, independent of the $\mathrm{CD} 11 \mathrm{~b}^{+}$macrophage population.

During high-fat diet-induced NASH, p65 was found to translocate to the nuclei of hepatocytes and drive production of tumor necrosis factor- $\alpha$ and IL-6 downstream of signaling from toll-like receptor 4 engaging with highmobility group box $1 .^{36}$ Hepatocytes have also been shown to produce tumor necrosis factor, IL-6, and CCL2 in many additional contexts (lipopolysaccharide, bacterial hepatotoxin, hepatocyte growth factor, and infection with Porphyromonas gingivalis). ${ }^{37,38}$ Of note, the hepatocytes used in this study were purified by differential centrifugation and may contain $5 \%$ to $15 \%$ NPCs, which could explain some of the observed changes in inflammatory gene expression. However, $\mathrm{F} 4 / 80^{+} \mathrm{CD} 11 \mathrm{~b}^{+}$hepatic macrophages, purified by double magnetic selection, showed modest down-regulation in transcript levels of Il6, Tnf, and $C c l 2$, suggesting these cells are not the source of inflammatory gene signatures. The influence of other NPCs, especially endothelial cells and stellate cells, on the inflammatory gene expression in the aged liver remains an area of future study.

The accumulation of $\mathrm{F} 4 / 80^{+} \mathrm{CD} 11 \mathrm{~b}^{+}$macrophages in the aged liver presented herein is a novel finding. To our knowledge, only one other study has systematically examined the effect of aging on liver-resident macrophages. Hilmer et $\mathrm{al}^{39}$ determined that the number and basal activity of Kupffer cells were increased with age in a rat model. However, this work was performed before the heterogeneity of hepatic macrophages was fully understood. Our work builds on this study, demonstrating an increase in the total $\mathrm{F} 4 / 80^{+}$macrophage pool and specifically the cells also expressing $\mathrm{CD} 11 \mathrm{~b}$, thought to be derived from circulating monocyte progenitors. CD11b was found to be expressed on both small, motile monocytes/macrophages organized in clusters as well as on spindle-shaped cells throughout the hepatic parenchyma in livers from aged mice.

$\mathrm{CD} 11 \mathrm{~b}$ functionally encodes integrin $\alpha-\mathrm{M}$, one protein subunit of integrin $\alpha-\mathrm{M} \beta-2$ (alias Mac-1 and complement receptor 3), which mediates leukocyte adhesion, migration, and phagocytosis. ${ }^{40}$ The increase in CD11b may be related to changes in the migration of cells or microenvironment through which the cells migrate. The increase in CD11b expression may also represent a phenotypical change in resident Kupffer cells, in addition to an influx in monocytederived macrophages. Fate tracing experiments using chimeric mice will be necessary to confirm the origin of the $\mathrm{F} 4 / 80^{+} \mathrm{CD} 11 \mathrm{~b}^{+}$hepatic macrophages and further characterize the phenotype of these subsets. It was not surprising to us that in the absence of injury or manipulation, hepatic macrophage levels were stable from 3 to 15 months, and the increase in macrophages in 19-month-old livers correlated with the onset of mild steatosis in the mice.

As CCL2 was identified as a chemokine produced by aging hepatocytes that might influence macrophage dynamics, the CCL2-CCR2 signaling pathway was inhibited in a natural aging mouse model. Inhibiting the CCL2-CCR2 axis by various means has been successful in ameliorating liver steatosis and inflammation in several models of NAFLD/NASH. Baeck et al ${ }^{41}$ pharmacologically inhibited CCL2 with emapticap pegol (NOX-E36) in methioninecholine deficient diet-induced NASH, and successfully diminished macrophage infiltration and steatohepatitis. Another group found that CCL2 knockout mice on the methionine-choline deficient diet had reduced fibrosis and inflammation in Balb/C strains. ${ }^{42}$ Similarly, CCR2 knockout mice in the C57BL/6 background maintained on choline-deficient amino acid-defined diet showed reduced steatosis, inflammatory cell infiltration, and fibrosis compared with the controls. ${ }^{43}$

In the present study, aged CCR2 KO mice exhibited attenuated levels of liver triglycerides and significant decreases in the inflammatory gene signature of hepatocyte cell fractions compared with their young counterparts. Although hepatocytes produce CCL2, they are not known to express CCR $2,{ }^{44}$ suggesting the changes in hepatocyte gene expression are secondary to other paracrine signaling pathways. This may be related to inhibiting the binding of other CCR2 ligands, such as CCL8, CCL7, and CCL12, in adipose tissue, stellate cells, or hepatic macrophage populations. ${ }^{44,45}$ Global changes in adipose tissue organization, metabolism, and inflammatory secretion may have influenced the observed changes in the liver and will be an area of future exploration.

Surprisingly, there was no change in the hepatic macrophage profile of aged CCR2 KO mice compared with the aged WT mice. Both aged cohorts displayed an overall increase in $\mathrm{F} 4 / 80^{+}$cells, specifically the $\mathrm{F} 4 /$ $80^{+} \mathrm{CD} 11 \mathrm{~b}^{+} \mathrm{CD} 68^{-}$subset, when compared with their young controls. These results suggest that the CCR2 KO mice may have adapted over time to loss of CCL2 or there may be compensation from other cytokine-signaling pathways in the aging liver responsible for macrophage recruitment. In addition, the global knockout of CCR2 may have led to systemic changes in adipose tissue that may influence the liver. A recent article by Kim et $\mathrm{al}^{46}$ demonstrated that adipocyte death and adipose-macrophage activation can directly impact metabolism and inflammation in the liver.

In addition to macrophage number, macrophage phenotype has been shown to play a role in fatty liver disease, where the presence of more M1 proinflammatory macrophages may result in a worse prognosis. ${ }^{47}$ The data suggest that the hepatic macrophages in the aged WT liver have a unique phenotype, where arginase expression is significantly up-regulated and the cells respond strongly to M1-polarizing cues by 
producing nitrate and increasing phagocytosis. Arginase-1 is typically associated with the alternative $\mathrm{M} 2$ activation state that can be permissive to fibrosis and progression of hepatocellular carcinoma after fatty liver disease. ${ }^{48}$ Intriguingly, one aged WT mouse died before reaching the 19-month time point and another was removed from the study because of tumors, whereas the CCR2 KO mice had no lethal pathologies. This may suggest that although the number of macrophages was not impacted by knocking out CCR2, macrophage phenotype may have been altered, but requires further study.

RNA-Seq analysis of aged WT livers revealed several other chemokines that might be involved in the recruitment of $\mathrm{F} 4 / 80^{+} \mathrm{CD}_{11 \mathrm{~b}^{+}}$macrophages, including $\mathrm{Cxcl}$, $\mathrm{Cxcl13}$, Ccl22, Ccl5, and Ccl6. Of note, $C c l 2$ was up-regulated but was not flagged as a significantly differentially expressed gene in the RNA-Seq screen because of the stringent filtering and false discovery rates. Others have found that CCL2 promotes the recruitment of CCR $2^{+} \mathrm{CD} 11 \mathrm{~b}^{+}$myeloid cells to metastatic cancer sites in the liver, but inhibition of CCL2 or CCR2 did not alter cell recruitment and had little effect on metastatic tumor burden. Deletion of the CD11 $b^{+}$ cells by diphtheria toxin receptor markedly decreased metastatic growth and incidence. ${ }^{49,50}$ Further studies will be necessary to determine which chemokines or signaling gradients are responsible for driving the increase in CD11bexpressing macrophages in the livers from aged mice, as well as the consequences of the increased macrophage presence in the liver.

Senescent cells accumulate with age in several organs, including the liver, and secrete signals that recruit immune cells for their subsequent removal. ${ }^{51}$ Senescent hepatocytes from male mice were found to undergo mitochondrial changes, leading to steatosis. ${ }^{5}$ In our cohort of female mice from the NIA, no changes were seen in transcripts of senescent markers $p 21, p 16$, or $p 50$ in the enriched hepatocytes. Increased nuclear localization of p21 staining was also not seen in the aged livers, suggesting that senescence is not the primary driver of fatty liver in this study. In addition, senescence-associated $\beta$-galactosidase staining did not show any change between the 3-month-old and 19month-old mice (data not shown). Senescence of other cell populations, such as Kupffer cells, could be one mechanism to explain the influx in $\mathrm{CD}_{11} \mathrm{~b}^{+}$macrophages with age; however, this will require more extensive investigation. Several methods have been used to eliminate senescent cells, including the INK-linked apoptosis through targeted activation of caspase (INK-ATTAC) mouse, which induces selective apoptosis downstream of a $\mathrm{p} 16^{\text {Ink4a }}$ promoter, but this method was partial and tissue specific, unable to eliminate senescent cells in the livers of female mice. ${ }^{52}$ One study performed in 20-month-old female mice identified lower oxygen consumption, lower complex IV, and higher complex I content in hepatic mitochondria, ${ }^{53}$ which could play a mechanistic role in the development of the fatty liver phenotype. Extended time points and further studies examining mitochondrial function and autophagy in livers from aged female mice may be warranted.

Our results suggest that inhibiting CCR2 signaling globally may be beneficial to reduce hepatic triglyceride levels and inflammatory gene expression in advanced age. Cenicriviroc, a dual CCR2/CCR5 antagonist, has now been shown in a phase $2 \mathrm{~b}$, randomized, double-blind, placebocontrolled, multinational clinical trial to improve nonalcoholic fatty liver disease activity score, with no concurrent worsening of fibrosis stage. ${ }^{54}$ The trial resulted in twice as many subjects achieving improvement in fibrosis and no worsening of steatohepatitis compared with placebo. ${ }^{55}$ Subgroup analysis demonstrated that the therapy was similarly effective in patients $>56$ and $<56$ years of age, suggesting this therapy may show promise in treating agerelated NAFLD/NASH as well. Our study lends further support that targeting the CCL2-CCR2 pathway may be a promising strategy to reduce the onset and progression of hepatic fat accumulation and inflammation during the process of aging.

\section{Acknowledgments}

We thank Lori A. Walton and Lynda Guzik (McGowan Institute for Regenerative Medicine); Carla Harris (Vanderbilt University Medical Center Lipid Core); Deborah Hollingshead and Dr. Janette Lamb (University of Pittsburgh Genomics Research Core), Dr. Ansuman Chattopadhyay and Sri Chaparala (Health Sciences Library System, University of Pittsburgh) for technical assistance; Drs. Wendy Mars, Donna Stolz, and William Wagner for encouragement and intellectual contributions; and the past and present members of the Brown laboratory for intellectual contributions or technical assistance: Branimir Popovich, Daniel Hachim, Aimon Iftikhar, Michael Buckenmeyer, Alexis Nolfi, Travis Prest, Brandon Burger, and Andrea Hartman.

\section{Supplemental Data}

Supplemental material for this article can be found at https://doi.org/10.1016/j.ajpath.2019.10.016.

\section{References}

1. Mikolasevic I, Filipec-Kanizaj T, Mijic M, Jakopcic I, Milic S, Hrstic I, Sobocan N, Stimac D, Burra P: Nonalcoholic fatty liver disease and liver transplantation: where do we stand? World J Gastroenterol 2018, 24:1491-1506

2. Wong RJ, Aguilar M, Cheung R, Perumpail RB, Harrison SA, Younossi ZM, Ahmed A: Nonalcoholic steatohepatitis is the second leading etiology of liver disease among adults awaiting liver transplantation in the United States. Gastroenterology 2015, 148:547-555

3. Younossi ZM, Koenig AB, Abdelatif D, Fazel Y, Henry L, Wymer M: Global epidemiology of nonalcoholic fatty liver disease: meta-analytic assessment of prevalence, incidence, and outcomes. Hepatology 2016, 64:73-84 
4. Petersen KF, Befroy D, Dufour S, Dziura J, Ariyan C, Rothman DL, DiPietro L, Cline GW, Shulman GI: Mitochondrial dysfunction in the elderly: possible role in insulin resistance. Science 2003, 300: $1140-1142$

5. Ogrodnik M, Miwa S, Tchkonia T, Tiniakos D, Wilson CL, Lahat A, Day CP, Burt A, Palmer A, Anstee QM, Grellscheid SN, Hoeijmakers JHJ, Barnhoorn S, Mann DA, Bird TG, Vermeij WP, Kirkland JL, Passos JF, von Zglinicki T, Jurk D: Cellular senescence drives age-dependent hepatic steatosis. Nat Commun 2017, 8:15691

6. Mohamad M, Mitchell SJ, Wu LE, White MY, Cordwell SJ, Mach J, Solon-Biet SM, Boyer D, Nines D, Das A, Catherine Li SY, Warren A, Hilmer SN, Fraser R, Sinclair DA, Simpson SJ, de Cabo R, Le Couteur DG, Cogger VC: Ultrastructure of the liver microcirculation influences hepatic and systemic insulin activity and provides a mechanism for age-related insulin resistance. Aging Cell 2016, 15:706-715

7. Gonzalez-Rodriguez A, Mayoral R, Agra N, Valdecantos MP, Pardo V, Miquilena-Colina ME, Vargas-Castrillon J, Lo Iacono O, Corazzari M, Fimia GM, Piacentini M, Muntane J, Bosca L, GarciaMonzon C, Martin-Sanz P, Valverde AM: Impaired autophagic flux is associated with increased endoplasmic reticulum stress during the development of NAFLD. Cell Death Dis 2014, 5:e1179

8. Duval C, Thissen U, Keshtkar S, Accart B, Stienstra R, Boekschoten MV, Roskams T, Kersten S, Muller M: Adipose tissue dysfunction signals progression of hepatic steatosis towards nonalcoholic steatohepatitis in C57BL/6 mice. Diabetes 2010, 59: 3181-3191

9. Kumar A, Sharma A, Duseja A, Das A, Dhiman RK, Chawla YK, Kohli KK, Bhansali A: Patients with nonalcoholic fatty liver disease (NAFLD) have higher oxidative stress in comparison to chronic viral hepatitis. J Clin Exp Hepatol 2013, 3:12-18

10. Bieghs V, Rensen PC, Hofker MH, Shiri-Sverdlov R: NASH and atherosclerosis are two aspects of a shared disease: central role for macrophages. Atherosclerosis 2012, 220:287-293

11. Tacke F, Zimmermann HW: Macrophage heterogeneity in liver injury and fibrosis. J Hepatol 2014, 60:1090-1096

12. Lanthier N: Targeting Kupffer cells in non-alcoholic fatty liver disease/non-alcoholic steatohepatitis: why and how? World J Hepatol 2015, 7:2184-2188

13. Jenkins SJ, Ruckerl D, Cook PC, Jones LH, Finkelman FD, van Rooijen N, MacDonald AS, Allen JE: Local macrophage proliferation, rather than recruitment from the blood, is a signature of $\mathrm{TH} 2$ inflammation. Science 2011, 332:1284-1288

14. Schulz C, Gomez Perdiguero E, Chorro L, Szabo-Rogers H, Cagnard N, Kierdorf K, Prinz M, Wu B, Jacobsen SE, Pollard JW, Frampton J, Liu KJ, Geissmann F: A lineage of myeloid cells independent of Myb and hematopoietic stem cells. Science 2012, 336:86-90

15. Yona S, Kim KW, Wolf Y, Mildner A, Varol D, Breker M, StraussAyali D, Viukov S, Guilliams M, Misharin A, Hume DA, Perlman H, Malissen B, Zelzer E, Jung S: Fate mapping reveals origins and dynamics of monocytes and tissue macrophages under homeostasis. Immunity 2013, 38:79-91

16. Gomez Perdiguero E, Klapproth K, Schulz C, Busch K, Azzoni E, Crozet L, Garner H, Trouillet C, de Bruijn MF, Geissmann F, Rodewald HR: Tissue-resident macrophages originate from yolk-sacderived erythro-myeloid progenitors. Nature 2015, 518:547-551

17. Kinoshita M, Uchida T, Sato A, Nakashima M, Nakashima H, Shono S, Habu Y, Miyazaki H, Hiroi S, Seki S: Characterization of two F4/80-positive Kupffer cell subsets by their function and phenotype in mice. J Hepatol 2010, 53:903-910

18. Scott CL, Zheng F, De Baetselier P, Martens L, Saeys Y, De Prijck S, Lippens S, Abels C, Schoonooghe S, Raes G, Devoogdt N, Lambrecht BN, Beschin A, Guilliams M: Bone marrow-derived monocytes give rise to self-renewing and fully differentiated Kupffer cells. Nat Commun 2016, 7:10321

19. Nakashima H, Nakashima M, Kinoshita M, Ikarashi M, Miyazaki H, Hanaka H, Imaki J, Seki S: Activation and increase of radio-sensitive
$\mathrm{CD} 11 \mathrm{~b}+$ recruited Kupffer cells/macrophages in diet-induced steatohepatitis in FGF5 deficient mice. Sci Rep 2016, 6:34466

20. Tacke F: Targeting hepatic macrophages to treat liver diseases. J Hepatol 2017, 66:1300-1312

21. Chinenov Y, Gupte R, Rogatsky I: Nuclear receptors in inflammation control: repression by GR and beyond. Mol Cell Endocrinol 2013, 380:55-64

22. Ballestri S, Nascimbeni F, Baldelli E, Marrazzo A, Romagnoli D, Lonardo A: NAFLD as a sexual dimorphic disease: role of gender and reproductive status in the development and progression of nonalcoholic fatty liver disease and inherent cardiovascular risk. Adv Ther 2017, 34:1291-1326

23. Overturf K, Al-Dhalimy M, Tanguay R, Brantly M, Ou CN, Finegold M, Grompe M: Hepatocytes corrected by gene therapy are selected in vivo in a murine model of hereditary tyrosinaemia type I. Nat Genet 1996, 12:266-273

24. Karimian A, Ahmadi Y, Yousefi B: Multiple functions of p21 in cell cycle, apoptosis and transcriptional regulation after DNA damage. DNA Repair (Amst) 2016, 42:63-71

25. Holt MP, Cheng L, Ju C: Identification and characterization of infiltrating macrophages in acetaminophen-induced liver injury. J Leukoc Biol 2008, 84:1410-1421

26. Thevaranjan N, Puchta A, Schulz C, Naidoo A, Szamosi JC, Verschoor CP, Loukov D, Schenck LP, Jury J, Foley KP, Schertzer JD, Larche MJ, Davidson DJ, Verdu EF, Surette MG, Bowdish DME: Age-associated microbial dysbiosis promotes intestinal permeability, systemic inflammation, and macrophage dysfunction. Cell Host Microbe 2017, 21:455-466.e4

27. Tchkonia T, Morbeck DE, Von Zglinicki T, Van Deursen J, Lustgarten J, Scrable H, Khosla S, Jensen MD, Kirkland JL: Fat tissue, aging, and cellular senescence. Aging Cell 2010, 9:667-684

28. Palikaras K, Mari M, Petanidou B, Pasparaki A, Filippidis G, Tavernarakis N: Ectopic fat deposition contributes to age-associated pathology in Caenorhabditis elegans. J Lipid Res 2017, 58:72-80

29. Arner P, Bernard S, Appelsved L, Fu KY, Andersson DP, Salehpour M, Thorell A, Ryden M, Spalding KL: Adipose lipid turnover and long-term changes in body weight. Nat Med 2019, 25: $1385-1389$

30. Maeso-Diaz R, Ortega-Ribera M, Fernandez-Iglesias A, Hide D, Munoz L, Hessheimer AJ, Vila S, Frances R, Fondevila C, Albillos A, Peralta C, Bosch J, Tacke F, Cogger VC, GraciaSancho J: Effects of aging on liver microcirculatory function and sinusoidal phenotype. Aging Cell 2018, 17:e12829

31. Turola E, Petta S, Vanni E, Milosa F, Valenti L, Critelli R, Miele L, Maccio L, Calvaruso V, Fracanzani AL, Bianchini M, Raos N, Bugianesi E, Mercorella S, Di Giovanni M, Craxi A, Fargion S, Grieco A, Camma C, Cotelli F, Villa E: Ovarian senescence increases liver fibrosis in humans and zebrafish with steatosis. Dis Model Mech 2015, 8:1037-1046

32. Ludwig J, Viggiano TR, McGill DB, Oh BJ: Nonalcoholic steatohepatitis: Mayo Clinic experiences with a hitherto unnamed disease. Mayo Clin Proc 1980, 55:434-438

33. Cameron KM, Miwa S, Walker C, von Zglinicki T: Male mice retain a metabolic memory of improved glucose tolerance induced during adult onset, short-term dietary restriction. Longev Healthspan 2012, 1:3

34. Ibrahim SH, Hirsova P, Gores GJ: Non-alcoholic steatohepatitis pathogenesis: sublethal hepatocyte injury as a driver of liver inflammation. Gut 2018, 67:963-972

35. Weisberg SP, McCann D, Desai M, Rosenbaum M, Leibel RL, Ferrante AW Jr: Obesity is associated with macrophage accumulation in adipose tissue. J Clin Invest 2003, 112:1796-1808

36. Li L, Chen L, Hu L, Liu Y, Sun HY, Tang J, Hou YJ, Chang YX, Tu QQ, Feng GS, Shen F, Wu MC, Wang HY: Nuclear factor highmobility group box 1 mediating the activation of Toll-like receptor 4 signaling in hepatocytes in the early stage of nonalcoholic fatty liver disease in mice. Hepatology 2011, 54:1620-1630 
37. Takano M, Sugano N, Mochizuki S, Koshi RN, Narukawa TS, Sawamoto Y, Ito K: Hepatocytes produce tumor necrosis factor-alpha and interleukin-6 in response to Porphyromonas gingivalis. J Periodontal Res 2012, 47:89-94

38. Norris CA, He M, Kang LI, Ding MQ, Radder JE, Haynes MM, Yang Y, Paranjpe S, Bowen WC, Orr A, Michalopoulos GK, Stolz DB, Mars WM: Synthesis of IL-6 by hepatocytes is a normal response to common hepatic stimuli. PLoS One 2014, 9:e96053

39. Hilmer SN, Cogger VC, Le Couteur DG: Basal activity of Kupffer cells increases with old age. J Gerontol A Biol Sci Med Sci 2007, 62: 973-978

40. Solovjov DA, Pluskota E, Plow EF: Distinct roles for the alpha and beta subunits in the functions of integrin alphaMbeta2. J Biol Chem 2005, 280:1336-1345

41. Baeck C, Wehr A, Karlmark KR, Heymann F, Vucur M, Gassler N, Huss S, Klussmann S, Eulberg D, Luedde T, Trautwein C, Tacke F: Pharmacological inhibition of the chemokine CCL2 (MCP-1) diminishes liver macrophage infiltration and steatohepatitis in chronic hepatic injury. Gut 2012, 61:416-426

42. Galastri S, Zamara E, Milani S, Novo E, Provenzano A, Delogu W, Vizzutti F, Sutti S, Locatelli I, Navari N, Vivoli E, Caligiuri A, Pinzani M, Albano E, Parola M, Marra F: Lack of CC chemokine ligand 2 differentially affects inflammation and fibrosis according to the genetic background in a murine model of steatohepatitis. Clin Sci (Lond) 2012, 123:459-471

43. Miura K, Yang L, van Rooijen N, Ohnishi H, Seki E: Hepatic recruitment of macrophages promotes nonalcoholic steatohepatitis through CCR2. Am J Physiol Gastrointest Liver Physiol 2012, 302: G1310-G1321

44. Seki E, de Minicis S, Inokuchi S, Taura K, Miyai K, van Rooijen N, Schwabe RF, Brenner DA: CCR2 promotes hepatic fibrosis in mice. Hepatology 2009, 50:185-197

45. Tsou CL, Peters W, Si Y, Slaymaker S, Aslanian AM, Weisberg SP, Mack M, Charo IF: Critical roles for CCR2 and MCP-3 in monocyte mobilization from bone marrow and recruitment to inflammatory sites. J Clin Invest 2007, 117:902-909

46. Kim SJ, Feng D, Guillot A, Shen D, Liu F, Hwang S, Parker R, Seo W, He Y, Godlewski G, Jeong WI, Lin Y, Qin X, Kunos G, Gao B: Adipocyte death preferentially induces liver injury and inflammation via the activation of $\mathrm{CCR} 2(+)$ macrophages and lipolysis. Hepatology 2019, 69:1965-1982
47. Wan J, Benkdane M, Teixeira-Clerc F, Bonnafous S, Louvet A, Lafdil F, Pecker F, Tran A, Gual P, Mallat A, Lotersztajn S, Pavoine C: M2 Kupffer cells promote M1 Kupffer cell apoptosis: a protective mechanism against alcoholic and nonalcoholic fatty liver disease. Hepatology 2014, 59:130-142

48. Yeung OW, Lo CM, Ling CC, Qi X, Geng W, Li CX, Ng KT, Forbes SJ, Guan XY, Poon RT, Fan ST, Man K: Alternatively activated (M2) macrophages promote tumour growth and invasiveness in hepatocellular carcinoma. J Hepatol 2015, 62:607-616

49. Lim SY, Yuzhalin AE, Gordon-Weeks AN, Muschel RJ: Targeting the CCL2-CCR2 signaling axis in cancer metastasis. Oncotarget 2016, 7:28697-28710

50. Zhao L, Lim SY, Gordon-Weeks AN, Tapmeier TT, Im JH, Cao Y, Beech J, Allen D, Smart S, Muschel RJ: Recruitment of a myeloid cell subset (CD11b/Gr1 mid) via CCL2/CCR2 promotes the development of colorectal cancer liver metastasis. Hepatology 2013, 57: $829-839$

51. Baker DJ, Wijshake T, Tchkonia T, LeBrasseur NK, Childs BG, van de Sluis B, Kirkland JL, van Deursen JM: Clearance of p16Ink4apositive senescent cells delays ageing-associated disorders. Nature 2011, 479:232-236

52. Baker DJ, Childs BG, Durik M, Wijers ME, Sieben CJ, Zhong J, Saltness RA, Jeganathan KB, Verzosa GC, Pezeshki A, Khazaie K, Miller JD, van Deursen JM: Naturally occurring p16(Ink4a)-positive cells shorten healthy lifespan. Nature 2016, 530:184-189

53. Valencia AP, Schappal AE, Morris EM, Thyfault JP, Lowe DA, Spangenburg EE: The presence of the ovary prevents hepatic mitochondrial oxidative stress in young and aged female mice through glutathione peroxidase 1. Exp Gerontol 2016, 73:14-22

54. Friedman S, Sanyal A, Goodman Z, Lefebvre E, Gottwald M, Fischer L, Ratziu V: Efficacy and safety study of cenicriviroc for the treatment of non-alcoholic steatohepatitis in adult subjects with liver fibrosis: CENTAUR phase $2 \mathrm{~b}$ study design. Contemp Clin Trials 2016, 47:356-365

55. Friedman SLRV, Harrison SA, Abdelmalek MF, Aithal GP, Caballeria J, Francque S, Farrell G, Kowdley KV, Craxi A, Simon K, Fischer L, Melchor-Khan L, Vest J, Wiens BL, Vig P, Seyedkazemi S, Goodman Z, Wong VW, Loomba R, Tacke F, Sanyal A, Lefebvre E: A randomized, placebo-controlled trial of cenicriviroc for treatment of nonalcoholic steatohepatitis with fibrosis. Hepatology 2018, 67:1754-1767 